\title{
Sistemas petrolíferos e modelos de acumulação de hidrocarbonetos na Bacia de Santos
}

\author{
Hung Kiang Chang ${ }^{1}$, Mario Luis Assine ${ }^{1}$, Fernando Santos Corrêa ${ }^{1}$, Julio Setsuo Tinen ${ }^{1}$, \\ Alexandre Campane Vidal $^{2} \&$ Luzia Koike $^{2}$
}

\begin{abstract}
Resumo A Bacia de Santos foi formada a partir de processos de rifteamento durante a separação afroamericana, no Mesozóico. A acumulação de sedimentos ocorreu inicialmente em condições flúvio-lacustres, passando posteriormente por estágio de bacia evaporítica e evoluindo para uma bacia de margem passiva. A análise do potencial do sistema petrolífero da bacia possibilitou identificar dois sistemas petrolíferos: Guaratiba-Guarujá e Itajaí-Açu-Ilhabela. A Formação Guaratiba, principal geradora, ainda é pouco conhecida na bacia devido à existência de poucos poços. Por analogia à congênere e vizinha Bacia de Campos, os óleos de origem salina foram gerados a partir de rochas depositadas em ambiente lacustre salino durante o Aptiano. Tal analogia foi confirmada pelas análises de amostras de óleo de alguns poços. Nestas análises também foi identificada a contribuição de óleo de origem marinha, indicando que a rocha geradora Itajaí-Açu (Cenomaniano-Turoniano) está na janela de geração, especialmente nos baixos estruturais gerados pela halocinese. Os modelos de acumulação consideram Formação. Guaratiba como o principal gerador de hidrocarbonetos para reservatórios calcareníticos plataformais da Formação Guarujá e turbiditos (desde Albiano Superior até o Mioceno), bem como siliciclásticos e carbonáticos da fase rifte. A migração ocorre através de falhas, janelas de sal e carrierbeds. O selo é formado por folhelhos e calcilutitos intraformacionais, além da espessa camada de evaporitos que pode contribuir como selo para a seção rifte, especialmente em águas profundas. A grande espessura das seções do Cretáceo Médio e Superior é responsável pela sobrecarga, contribuindo significativamente para a geração e expulsão de hidrocarbonetos neste período. As trapas são do tipo estruturais (rollovers e casca-detartaruga), estratigráficas (pinch-outs de corpos arenosos) e mistas (pinch-outs de turbiditos contra a parede de domos salinos).
\end{abstract}

Palavras-chave: Bacia de Santos, sistemas petrolíferos, acumulações de petróleo.

Abstract Petroleum systems and hydrocarbon accumulation models in the Santos Basin. The Santos Basin was formed by rifting process during Mesozoic Afro-American separation. Sediment accumulation initiated with fluvial-lacustrine deposits, passing to evaporitic stage until reaching marginal basin stages. The analysis of hydrocarbon potential of Santos Basin identified two petroleum systems: Guaratiba-Guarujá and Itajaí-Açu-Ilhabela. The Guaratiba Formation is less known in the Santos Basin because of small number of wells that have penetrated the rift section. By comparison with Campos Basin, hydrocarbons are of salinelacustrine origin deposited in Aptian age. Analogous to Campos Basin the major source rock is of saline-lacustrine origin, which has been confirmed from geochemical analyses of oil samples recovered from the various fields. These analyses also identified marine source rock contribution, indicating the Itajaí-Açu source rock went through oil-window, particularly in structural lows generated by halokynesis. Models of hydrocarbon accumulation consider Guaratiba Formação as the major source rock for shallow carbonate reservoirs of Guarujá Formação and for late Albian to Miocene turbidites, as well as siliciclastic and carbonate reservoirs of the rift phase. Migration occurs along salt window and through carrier-beds. The seal rock is composed of shales and limestones intercalated with reservoir facies of the post-rift section and by thick evaporites overlying rift section, especially in the deeper water. In the shallow portion, shale inter-tongued with reservoir rocks is the main seal rock. The hydrocarbon generation and expulsion in the central-north portion of the basin is caused by overburden of a thick Senonian section. Traps can be structural (rollovers and turtle), stratigraphic (pinch-outs) and mixed origins (pinch-outs of turbidites against salt domes).

Keywords: Santos Basin, petroleum system and petroleum accumulation models.

INTRODUÇÃO A história de exploração de petróleo da Bacia de Santos iniciou-se nos anos 70, quando ocorreram as primeiras incursões exploratórias, porém sem sucesso. Este período foi marcado por descobertas terrestres, na Bacia do Espírito Santo (Campo de São Mateus, e marítimas, nas bacias Potiguar (Campo de

1 - Laboratório de Estudos de Bacias (LEBAC), UNESP, Rio Claro (SP), Brasil. E-mails: chang@rc.unesp.br, assine@rc.unesp.br, fscorrea@rc.unesp.br e jstinen@rc.unesp.br

2 - Centro Estudos de Petróleo (CEPETRO), UNICAMP, Campinas (SP), Brasil. E-mails: vidal@ige.unicamp.br; luzia@iqm.unicamp.br 
Ubarana) e de Campos (Campo de Garoupa).

Entre meados da década de 70 e de 80 , a Bacia de Campos se firmou como produtora de petróleo e, em virtude da segunda crise do petróleo e da necessidade do aumento da produção doméstica de petróleo, criouse a política de exploração em contrato de risco. Assim, em 1980, a Pecten, fez a primeira descoberta na Bacia de Santos, em arenitos turbidíticos da Formação ItajaíAçu (Pereira \& Macedo 1990, Pereira 1994), no campo de Merluza. Vale destacar que neste período foram descobertos os campos gigantes de Namorado, Marlim e Albacora (Bacia de Campos).

As descobertas dos campos de Tubarão, Coral, Estrela do Mar e Caravela em reservatórios carbonáticos albianos no sul da Bacia de Santos, a partir da década de 80 , aumentaram as expectativas de uma grande bacia petrolífera, o que se confirmou nos últimos anos, com as descobertas de Mexilhão, Tupi e Júpiter.

Após a criação da nova lei do petróleo, de 1997, a Bacia de Santos recebeu novamente atenção exploratória da Petrobras e de outras companhias estrangeiras e nacionais. Novas descobertas foram realizadas, especialmente na porção norte da bacia, como os campos de Oliva, Atlanta, Lagosta, Tambuatã, Tambaú, Mexilhão, Carápia, Uriguá e Pirapitanga. Recentemente, duas grandes descobertas feitas pela Petrobras, os campos de Tupi e Júpiter, abriram novos horizontes à exploração de petróleo na bacia, atingindo a porção superior da seção rifte, em profundidades superiores a $6500 \mathrm{~m}, \log$ o abaixo de espessa camada de evaporitos, em águas ultra-profundas (lâmina d'água superior a $2500 \mathrm{~m}$ ). As reservas estimadas do campo de Tupi estão entre 6 e 8 bilhões de barris, correspondendo a cerca de 50 a $60 \%$ de toda a reserva nacional atual, o que traduz o grande potencial desta nova fronteira exploratória.

A primeira contribuição para o conhecimento da Bacia de Santos foi o trabalho de reconhecimento regional feito por Meister (1973) apud Gonçalves et al. (1979), que destaca aspectos estruturais das bacias de Pelotas e Santos. Trabalhos mais recentes sobre a evolução geodinâmica da Bacia de Santos e áreas adjacentes foram realizados por Azevedo Jr. (1991), Macedo (1987, 1989, 1990), Macedo \& Gambôa (1998), Cobbold et al. (2001), Mesling et al. (2001) e ANP (2003).

O esboço estratigráfico da coluna sedimentar da Bacia de Santos deve-se a Ojeda \& Cesero (1973) apud Gonçalves et al. (1979), que se basearam em dados de poços, formalizando a primeira carta estratigráfica da Bacia de Santos. Esta carta foi posteriormente complementada e modificada por Ojeda \& Silva (1975) apud Gonçalves et al. (1979), Pereira \& Macedo (1990), Pereira \& Feijó (1994), ANP (2003) e Modica \& Brush (2004).

As análises sismo-estratigráficas para interpretação de sistemas deposicionais, com ênfase à exploração de petróleo, foram feitas por Brown et al. (1975) apud Gonçalves et al. (1979). Essa análise foi complementada por técnicos da Petrobras, com a integração de dados geofísicos e geoquímicos para um modelo geológico da plataforma sul, visando objetivos favoráveis à prospecção de hidrocarbonetos. Trabalho semelhante também foi feito por Gonçalves et al. (1979) na tentativa de elucidar a evolução tectono-sedimentar da plataforma Continental Sul-brasileira, por meio de dados sísmicos e de poços.

A halocinese foi o principal agente causador das estruturas adiastróficas que modelaram a seção pós-rifte da Bacia de Santos. Essas estruturas apresentam importante influência nas acumulações de petróleo, especialmente com relação à migração e à geração de trapas (Pereira \& Macedo 1990, Demercian \& Szatmari 1993, Szatmari et al. 1994, Demercian 1996 e Ge et al. 1996).

Pereira \& Macedo (1990) apresentaram um panorama geral da Bacia de Santos, desde aspectos genéticos até seus principais plays exploratórios. Os autores destacaram a Formação Guaratiba como a principal rocha geradora e a migração através de falhas, paredes dos diápiros e discordâncias estratigráficas. Apontaram como os principais plays petrolíferos as acumulações descobertas em calcarenitos oolíticos da Formação Guarujá e em arenitos turbidíticos do Membro Ilhabela. Também indicaram como plays os arenitos costeiros/ marinhos rasos da porção inferior da Formação Juréia, sobre almofadas de sal; os arenitos continentais/marinhos da porção superior da Formação Juréia, em ápice de domos; os arenitos turbidíticos da porção médioinferior da Formação Santos (águas profundas); e os arenitos turbidíticos terciários da Formação Marambaia (águas profundas).

O presente trabalho é fruto do projeto intitulado "Interpretação e Mapeamento dos Sistemas Petrolíferos da Bacia de Santos" (convênio UNESP-ANP 2002). O estudo consistiu na interpretação sísmica de 11 horizontes que constituem o arcabouço geológico-estrutural da bacia; na análise estratigráfica de 145 poços por meio de seções-geológicas que permitiram a subdivisão vertical da bacia em 14 seqüências deposicionais separadas por discordâncias regionais; no processamento e interpretação de dados magnetométricos e gravimétricos que nortearam a construção do arcabouço estrutural do embasamento da bacia; e nas análises geoquímicas de óleos provindos dos campos de produção, que auxiliaram na interpretação da origem da rocha geradora e nas modelagens geoquímicas de maturidade, geração e expulsão de hidrocarbonetos.

Neste trabalho procedeu-se à integração de informações geofísicas, geoquímicas e geológicas, aliada a ferramentas de processamento, o que permitiu a obtenção de dados sobre a época de geração e expulsão de hidrocarbonetos, bem como a definição dos principais modelos de acumulações responsáveis por reservas da ordem de $120 \mathrm{Mbbl}$, na seção pós-rifte, e da ordem de 6 a 8 Bbbl, na seção rifte.

GEOLOGIA DA BACIA DE SANTOS A Bacia de Santos está localizada na região sudeste da margem continental brasileira (Fig. 1), defronte aos estados do Rio de Janeiro, São Paulo, Paraná e Santa Catarina, englobando uma área de $352.000 \mathrm{~km}^{2}$ e contendo espessuras sedimentares superiores a $10 \mathrm{~km}$ nos principais depocentros.

A grande dimensão aliada à escassez de dados e 


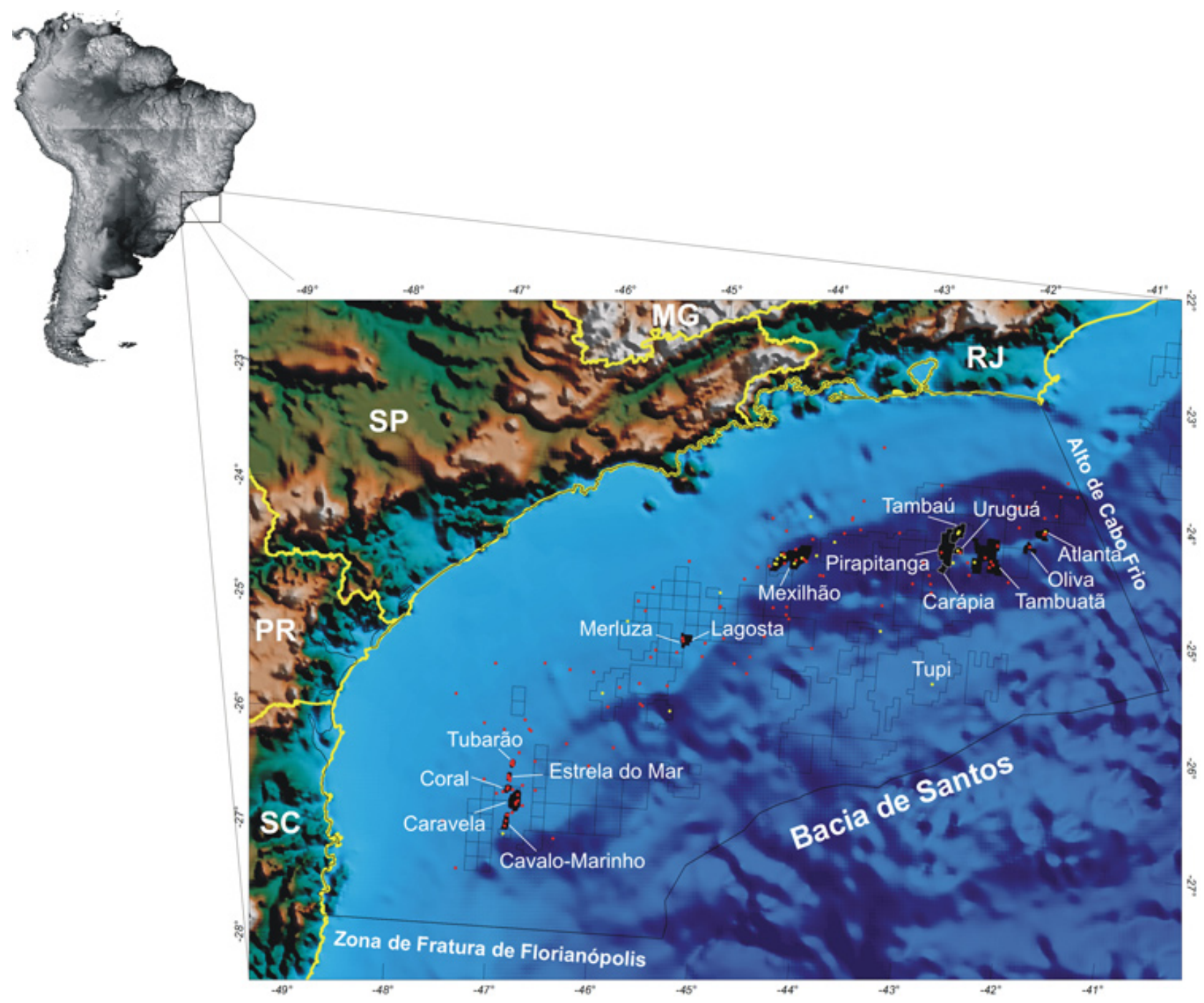

Figura 1 - Mapa de localização da Bacia de Santos e áreas adjacentes. A imagem colorida resulta da integração do modelo digital de terreno (GTOPO30) e da batimetria da bacia. Os polígonos preenchidos correspondem aos campos produtores e os polígonos sem preenchimento aos blocos exploratórios. Os pontos em vermelho correspondem aos poços exploratórios públicos e os amarelos a poços exploratórios confidenciais.

informações sobre a geologia e os sistemas petrolíferos conferem-lhe o status de bacia pouco conhecida. Todavia, as recentes descobertas de óleo e gás destacam-na como uma grande e promissora fronteira exploratória petrolífera no Brasil.

A evolução da fase rifte da Bacia de Santos resulta da propagação da ruptura das placas sul-americana e africana, no Eo-Cretáceo. O rifte Sul-Atlântico propagou-se de sul para norte, controlado pela distribuição de tensões regionais que condicionou a atenuação litosférica em ampla faixa de deformação, com estruturas de direção aproximada N-NNE na porção sul da Bacia de Santos, com inflexão para N40-50E na porção norte de Santos e, novamente, inflexão para N-NNE a norte do Alto de Cabo Frio (Correa et al. 2007).

Durante o desenvolvimento da fase sin-rifte I (H0 - Fig. 2), ocorreu o confinamento dos esforços na porção da crosta que sofreu afinamento, provocando falhas crustais (Chang et al. 1992, Karner \& Driscoll
1999). A fase sin-rifte II desenvolveu-se com litosfera parcialmente afinada, o que levou à diminuição da tensão vertical $(\sigma 1)$. A redução da tensão mínima $(\sigma 3)$ condicionou a ruptura sob condições de diminuição crescente da resistência ao cisalhamento, configurando processo de strain softening e formação de sistemas de falhas balizadas por uma segunda linha de charneira. A deformação foi concentrada nas porções crustais superiores, com a formação de sistemas de falhas com ângulo de caimento menor que o das falhas da fase sin-rifte I, porém distribuídas por uma área mais ampla afetada por estiramento supra-crustal.

A fase sin-rifte III representou a evolução do processo de strain softening, cujo resultado final foi o rompimento litosférico (H1 - Fig. 2). Esta fase caracterizou-se por sistemas de falhas de pequena magnitude, concentradas na porção superior da seção rifte, com desenvolvimento de uma ampla depressão tipo sag, lateralmente contínua. A fase sin-rifte III parece tam- 


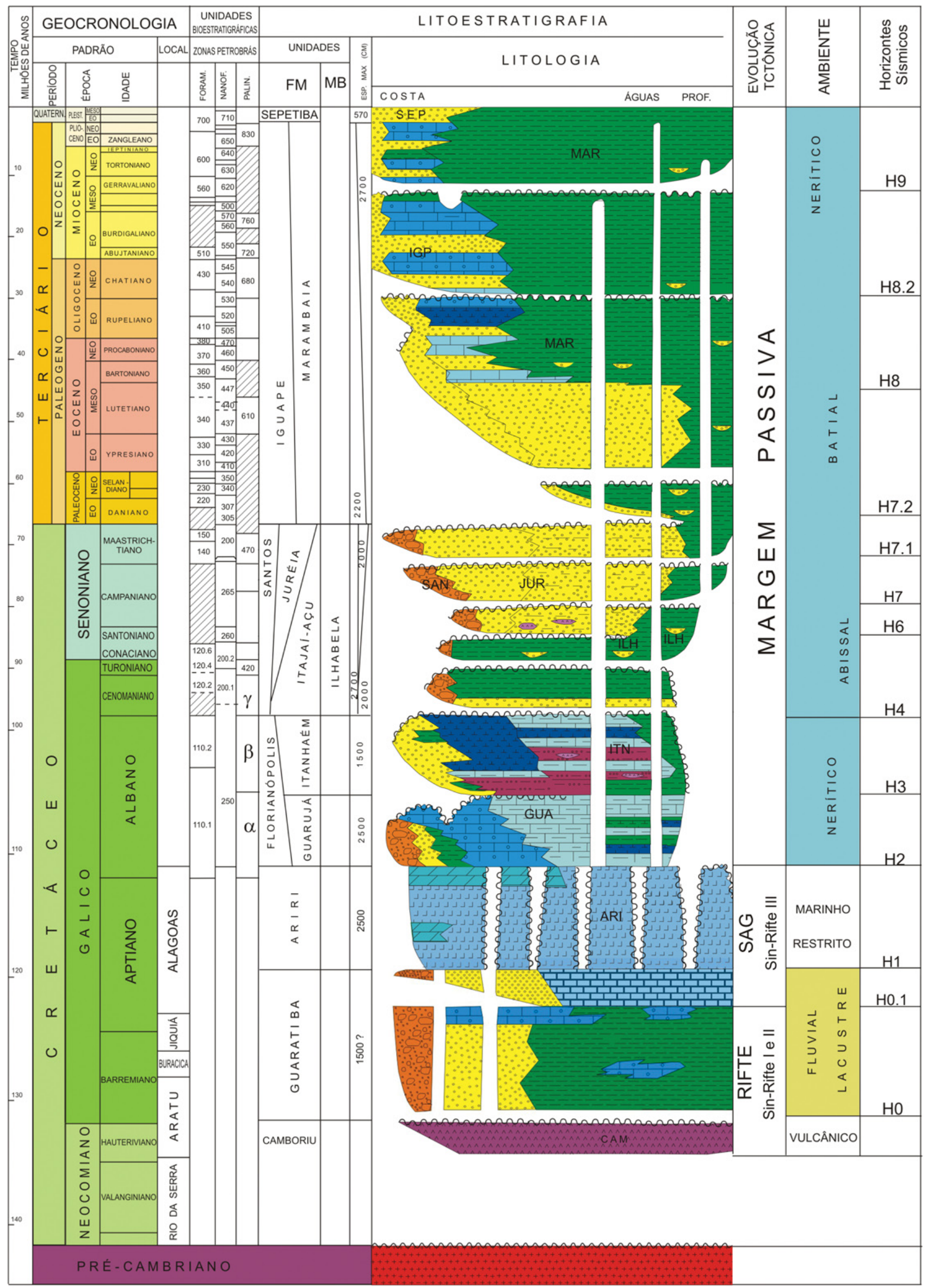

Figura 2 - Carta estratigráfica da Bacia de Santos (modificado de Pereira \& Feijó, 1994). 
bém refletir o início da subsidência térmica, já atuante previamente à ruptura litosférica definitiva, ou registrar processos de cisalhamento dúctil na base da crosta, tal como aventado por Karner \& Driscoll (1999). A principal rocha geradora de hidrocarbonetos da Bacia de Santos está posicionada estratigraficamente nesta fase.

A partir da fase sin-rifte III, ocorre na Bacia de Santos expressiva sedimentação evaporítica (H2 Fig. 2), condicionada pela presença de altos vulcânicos (Dorsal de São Paulo) que causaram restrição à circulação de águas do oceano provindas de sul, além do clima seco e quente vigente à época (Demercian 1996). Durante a fase de transição (Pereira \& Feijó 1994), as taxas de evaporação eram altas em relação ao influxo de água, proporcionando a deposição de espessos pacotes de sal que podem atingir espessuras de 2000 a $2500 \mathrm{~m}$ (Chang et al. 1990, Pereira \& Macedo 1990) (Fig. 2).

Após a sedimentação evaporítica instala-se um sistema deposicional misto, com acumulação de siliciclásticos na borda (Formação Florianópolis) e de carbonatos na porção mais distal (Formação Guarujá) (H3 - Fig. 2). Com a deposição destas seqüências instala-se um sistema marinho na bacia, porém em ambiente hipersalino, com pouca circulação de água oceânica, refletido na escassez e pouca diversidade da biota que compõe os carbonatos. Vivers \& Azevedo (1988) descrevem a predominância de seres bentônicos em relação aos seres plantônicos, o que seria um forte indício da restrição à circulação de água na região sul da bacia, mesmo durante a deposição da Formação Guarujá (Carvalho et al. 1990).

A plataforma carbonática experimenta uma subsidência expressiva no Neo-Albiano, culminando com a deposição de calcilutitos em ambiente nerítico profundo, onde a fauna é rica e mais diversificada, com predomínio de seres plantônicos (Vivers \& Azevedo 1988). Um nível glauconítico (Nível G) em meio aos calcilutitos marca o final da fase trangressiva (Chang et al. 1990). Sobre este nível se desenvolve um trato de sistema de mar alto (Pereira 1994), caracterizado pelo aumento de terrígenos nas porções proximais e de calcilutitos e margas nas porções distais, que persiste até o início do Cenomaniano, quando ocorre a completa extinção da plataforma carbonática (Formação Itanhaém) (H4 - Fig. 2).

A plataforma carbonática já apresentava indício da halocinese, como crescimento de seções meso-albianas contra as falhas recém-geradas e almofadas e diápiros de sal, principalmente na porção sul, onde a deposição da seção sobreposta, no intervalo do neo-albiano ao turoniano, apresenta suas maiores espessuras.

Os campos petrolíferos da porção sul da bacia estão localizados nos trends de estruturas cascas-de-tartaruga criadas pela halocinese, resultando em geometria propícia à acumulação nos reservatórios carbonáticos da Formação Guarujá.

Pereira et al. (1994) descreve um nível de arenitos sobre o topo da Formação Itanhaém que estaria relacionado a depósitos de trato de mar baixo, evidenciando o início da grande transgressão do topo da época gálica (Cenomaniano-Turoniano), representada na bacia pela Formação Itajaí-Açu. É importante ressaltar que na base desta seqüência está posicionada a principal rocha geradora da fase pós-rifte (Pereira et al. 1986), podendo ser correlacionada mundialmente com o segundo evento anóxico do Cretáceo (OAE-2, Arai 1988). Pereira (1994) individualiza a Formação ItajaíAçu em dois níveis de folhelhos radioativos, enriquecidos em matéria orgânica (CNsT1 e CNsT2), sendo o CNsT2 correlato ao OAE-2. No presente trabalho, a nomenclatura dada a esse intervalo é $\mathrm{H} 4-\mathrm{H} 5$.

Após o ápice da transgressão, materializada pela superfície de máxima inundação (H5), desenvolve-se um trato de mar alto representado por folhelhos que gradam para siltitos e arenitos finos (Pereira 1994, Demercian 1996, ANP 2004). Os arenitos turbidíticos pertencem ao Membro Ilhabela e se depositaram nos baixos estruturais gerados pela ascensão de diápiros de sal. Estes turbiditos são os principais reservatórios desta seqüência, incluindo os campos de Merluza e Lagosta.

Após a transgressão neo-albiana-coniaciana, instalou-se um megaevento regressivo na bacia que está intimamente relacionado ao soerguimento da Serra do Mar (Pereira et al. 1986, Pereira \& Macedo 1989, Macedo 1990, ANP 2003 e Módica \& Brush 2004).

A deposição da seqüência senoniana restringiuse à Calha Central da Bacia de Santos, sendo reconhecida por Demercian et al. (1993) como a deposição sedimentar no bloco baixo de uma falha antitética, de origem halocinética, que se estende por toda a parte central da bacia, com direção NE-SW.

A deposição na Calha Central ou Zona de Falhas de Cabo Frio (Mohriak et al. 1995) iniciou com turbiditos de leque de assoalho em trato de mar baixo. Neste trabalho, as areias turbidíticas da seção senoniana não são consideradas como pertencentes ao Membro Ilhabela, como descrevem Pereira \& Macedo (1989). Optou-se, aqui, por restringir o posicionamento estratigráfico do Membro Ilhabela à seção da Formação ItajaíAçu, para não confundir com os depósitos turbidíticos da seção senoniana (Formação Santos/Juréia).

A deposição prossegue em um sistema progradante de nível de mar baixo (Pereira 1994), onde no topo da cunha progradante as areias constituem ilhas barreiras e praias, segundo Pereira (1990). Estas areias são importantes reservatórios desta idade, contudo há problemas com as rochas selantes. Após este episódio, é identificada uma seção transgressiva seguida de depósitos de trato de mar alto agradacional e progradacional (K100 - Fig. 2), constituídos por leques aluviais, rios e depósitos costeiros que se interdigitam com sistemas marinhos (Pereira et al. 1986).

Outros pulsos ocorrem do Campaniano Inferior ao Campaniano Superior (K110, Fig. 2) e do Campaniano Superior ao Cretáceo Superior (K120 - Fig. 2), com sistemas deposicionais semelhantes aos anteriores, exibindo transgressões mais discretas e maior influência marinha, com flora e fauna indicativas de situação proximal (Demercian 1996). Estes eventos foram responsáveis pelo avanço para leste de mais de $200 \mathrm{~km}$ da linha de costa em relação à atual (Fig. 3). 
O topo da seção senoniana e/ou cretácea na Bacia de Santos é marcado por ampla discordância regional (Macedo 1990).

A mais expressiva feição estrutural pós-sal na bacia ocorre devido à deposição da seção senoniana sobre a Calha Central (Demercian 1996), causando o deslocamento quase completo do sal para porções mais profundas da bacia, o que ocasionou a tectônica de rafts (seção albiana) e a criação de uma importante janela de sal, da ordem de $20 \mathrm{~km}$ de comprimento. Desta forma, a rocha geradora foi colocada em contato direto com potencias reservatórios e trapas, favoráveis à acumulação de hidrocarbonetos.

A seção terciária da Bacia de Santos é bem marcada por duas discordâncias: Oligoceno Inferior a Médio e Mioceno Médio. No Eoceno instalou-se um sistema de mar baixo com cunhas progradantes e onlap costeiro, propiciando a formação de importantes reservatórios turbidíticos na base destas cunhas.

No geral, a seção terciária da bacia é composta por fandeltas nas porções proximais, passando para plataformas carbonáticas da Formação Sepetiba, e para depósitos de talude e de bacia profunda da Formação Marambaia (Pereira et al. 1986).

ROCHAS GERADORAS Na Bacia de Santos ocorrem dois intervalos geradores de hidrocarbonetos: a porção superior da Formação Guaratiba e a porção inferior da Formação Itajaí-Açu.

$\mathrm{O}$ conhecimento sobre estas rochas geradoras limita-se às análises geoquímicas realizadas em amostras de óleo provindas das acumulações comerciais e sub-comerciais. Isso porque, poucos poços de petróleo atingiram a seqüência sin-rifte III. Já outras características da rocha geradora, como espessura, área de ocorrência, estado de deformação, podem ser obtidas por meio de dados sísmicos. Em direção às águas profundas, supõe-se que as características geoquímicas (car- bono orgânico total, potencial gerador e qualidade da matéria orgânica) e geológicas (espessura e continuidade lateral) sejam compatíveis com a geração de hidrocarbonetos, como encontrado nas últimas descobertas (Campo de Tupi).

Análises de biomarcadores em amostras de óleo provindas de 15 amostras selecionadas ao longo da bacia (Fig. 4a) diagnosticaram provável fonte do óleo como sendo lacustre salino com contribuição marinha siliciclástica, como pode ser observado na figura 4.

Os parâmetros dos hidrocarbonetos foram obtidos por cálculos de integração da altura dos picos dos cromatogramas de íons: lineares (Fig. 4e), terpanos (Fig. 4f) e esteranos (Fig. 4g). Tais cromatogramas mostram os perfis característicos de todos os óleos estudados na amostra AM2.

Os resultados sobre a origem dos óleos indicam que a Formação Itajaí-Açu entrou na janela de geração em diferentes locais da bacia. Tanto é verdade que três amostras apresentam características típicas marinhas e outras duas amostras estão localizadas no campo dos óleos de origem marinha, em somente um dos parâmetros utilizados: tricíclico C24/C21 x tricíclico C26/C25 e pentacíclico $\mathrm{C} 31 / \mathrm{C} 30 \times$ tricíclico $\mathrm{C} 26 / \mathrm{C} 25$, respectivamente (Fig. 4).

Rocha Geradora Guaratiba Os óleos de origem salina foram gerados a partir de rochas depositadas em ambiente lacustre salino (Formação Guaratiba), durante o Aptiano (andar Alagoas), no estágio final da fase rifte (sin-rifte III), quando o sistema de lagos passou a receber influência de águas salinas provindas do sul, tornando-se salinizado em função do incremento de aridez no final do Cretáceo Inferior. Por correlação com a Formação Lagoa Feia (Bacia de Campos), especula-se que a unidade seja formada por folhelhos negros laminados, intercalados com carbonatos, com espessura variando de 100 a 300 metros, concentração de Carbono Orgânico Total

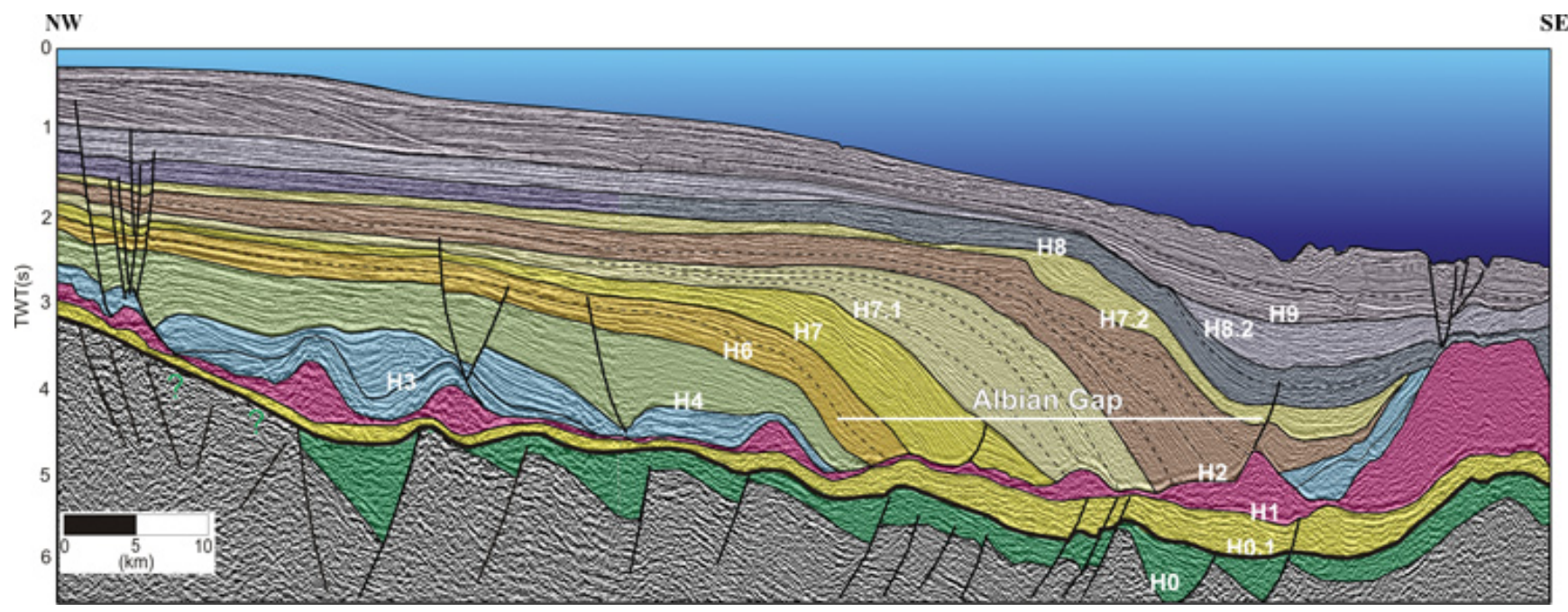

Figura 3 - Seção sísmica migrada em tempo, exemplificado o arcabouço estratigráfico da porção norte da Bacia de Santos. Horizontes estratigráficos podem ser verificados na figura 2. 

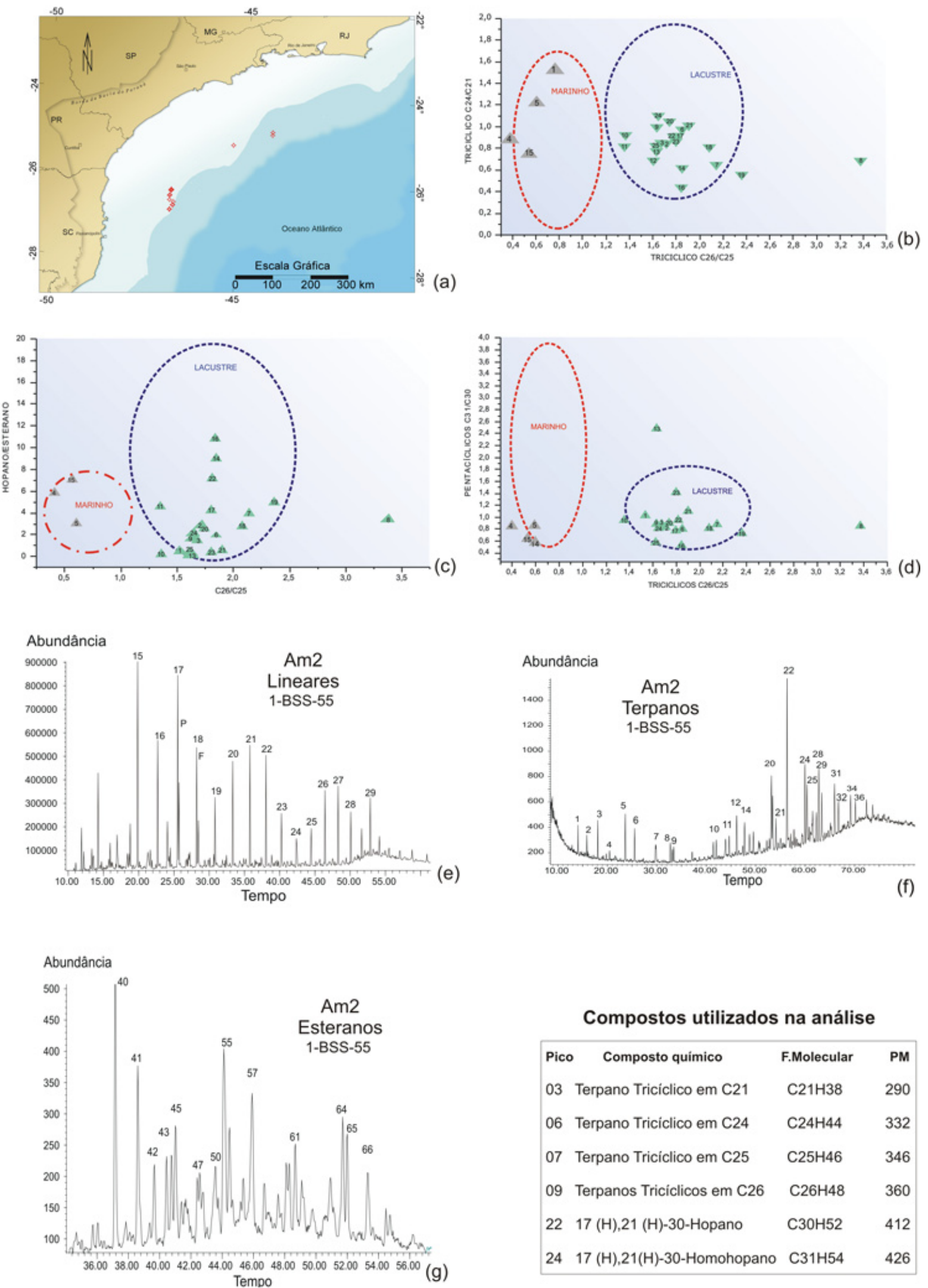

\section{Compostos utilizados na análise}

\begin{tabular}{|lllr|}
\hline Pico & Composto químico & F.Molecular & PM \\
03 & Terpano Tricíclico em C21 & C21H38 & 290 \\
06 & Terpano Triciclico em C24 & C24H44 & 332 \\
07 & Terpano Tricíclico em C25 & C25H46 & 346 \\
09 & Terpanos Tricíclicos em C26 & C26H48 & 360 \\
22 & $17(H), 21(H)-30-H o p a n o$ & C30H52 & 412 \\
24 & $17(H), 21(H)-30-H o m o h o p a n o$ & C31H54 & 426 \\
\hline
\end{tabular}

Figura 4 - Gráficos resultantes da análise geoquímica dos compostos dos óleos da Bacia de Santos. (a) Mapa de localização das amostras de óleo; (b) Gráfico de correlação entre Tricíclicos; (c) Gráfico de correlação entre Tricíclicos e Hopanoesterano; (d) Gráfico de correlação entre Tricíclicos e Pentaciclicos; (e) Cromatograma de ions dos hidrocarbonetos lineares (amostra AM02 - 1BSS0055); (f) Cromatograma de ions dos hidrocarbonetos referente à familia dos terpanos (amostra AM02 - 1BSS-0055); (g) Cromatograma de ions dos hidrocarbonetos referentes ao componentes esteranos (amostra AM02 - 1BSS-0055). 
(TOC) variando de 2 a $6 \%$ e Índice de Hidrogênio (HI) superior a $900 \mathrm{mg}$ de $\mathrm{HC} / \mathrm{g} \mathrm{TOC}$, indicando tratar-se de querogênio do tipo I. Os óleos se caracterizam por apresentar altos teores de hidrocarbonetos saturados, relativa abundância de n-alcanos de elevado peso molecular, teores médios de enxofre $(\sim 0.3 \%)$, alta razão $\mathrm{V} / \mathrm{Ni}$, presença de $\beta$-caroteno e relativa abundância de gamacerano (Mello et al. 1988). A figura 5 mostra um perfil geoquímico típico da Formação Lagoa Feia.

Rocha Geradora Itajaí-Açu Um intervalo com importantes características de rocha geradora é o referente à porção inferior da Formação Itajaí-Açu (Seqüência H4-H5 - Fig. 6a). Este intervalo é o que apresenta maior quantidade de dados geoquímicos disponíveis, uma vez que boa parte dos poços da bacia atravessou esta unidade. Esta, porém, encontra-se nos estágios iniciais de maturidade térmica, podendo apresentar condições de expulsão de hidrocarbonetos em baixos localizados, adjacentes aos grandes domos e diápiros de sal.

A deposição da unidade ocorreu em ambiente marinho anóxico, durante o Cenomaniano/Meso-Turoniano, período correlacionável ao segundo evento anóxico do Cretáceo (OAE-2). O valor de TOC médio para este intervalo encontra-se ao redor de $1 \%$, com máximo de $6 \%$. Já os valores médios de $\mathrm{S} 1$ e $\mathrm{S} 2$ são $0,41 \mathrm{mg} \mathrm{HC} / \mathrm{g}$ de rocha e $2,19 \mathrm{mg} \mathrm{HC} / \mathrm{g}$ de rocha, respectivamente. $\mathrm{O}$ gráfico da figura $6 \mathrm{~b}$ mostra que a matéria orgânica constitui mistura dos tipos II e III, condizente com a descrição apresentada por Arai (1988), sendo composta de algas marinhas, polens, esporos e fragmentos de vegetais terrestres.

RESERVATÓRIOS A Bacia de Santos possui boa variedade de rochas-reservatório, desde os carbonatos de água rasa da Formação Guarujá, até os arenitos turbidíticos eocênicos da Formação Marambaia. Os carbonatos oolíticos da Formação Guarujá constituem o reservatório mais importante da seção pós-rifte, devido ao maior volume de óleo descoberto nestas rochas, aglutinando os campos de Tubarão, Estrela do Mar, Coral, Caravela e Cavalo-Marinho. Por sua vez, o Membro Ilhabela da Formação Itajaí-Açu, composto por arenitos turbidíticos de idade neo-turoniana a eo-santoniana, que formam, entre outras acumulações sub-comerciais, os campos de Merluza e Lagosta, também constitui importante alvo exploratório.

Rochas Carbonáticas da Formação Guarujá Os carbonatos depositados em ambiente de águas rasas constituem importante reservatório na porção sul da Bacia de Santos. Foi nesta região que se desenvolveu extensa plataforma carbonática (Formação Guarujá) durante o Albiano Inferior-Médio e onde se localizam os campos de Tubarão, Estrela do Mar, Coral, Caravela e Cavalo-Marinho. Este reservatório é constituído de calcarenitos oolíticos de variada gama textural, essencialmente grainstones. O Campo de Tubarão, posicionado na porção sul da Bacia de Santos, é o principal exemplo deste tipo de reservatório. As zonas porosas

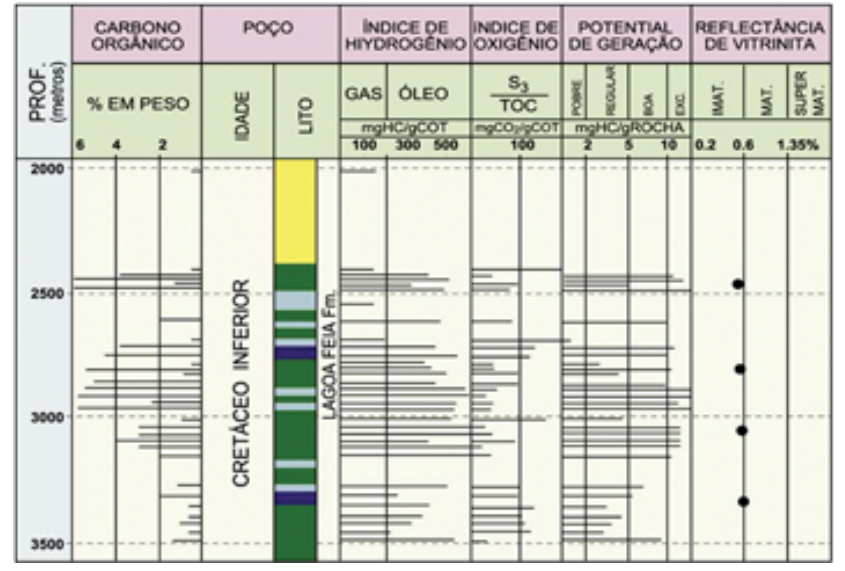

Figura 5 - Perfil geoquímico da Formação Lagoa Feia (Cretáceo Inferior) mostrando os folhelhos calciferos que formam a principal rocha geradora da Bacia de Campos (modificado de Mello et al. 1994).

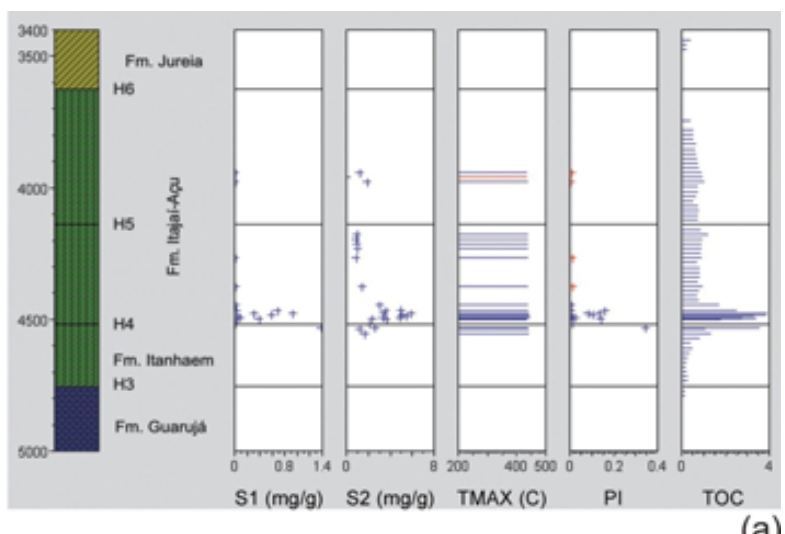

(a)

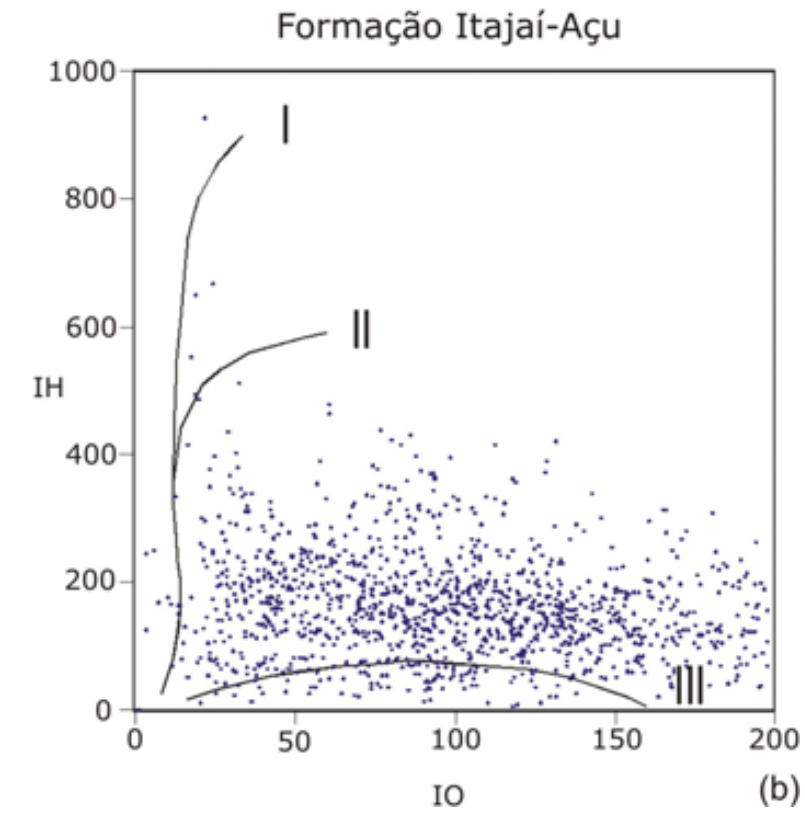

Figura 6 - Características geoquímicas da rocha geradora Itajai-Açu. (a) Perfil geoquímico do poço IPRS-003, mostrando a porção inferior da Formação Itajai-Açu, composta por folhelhos geradores com até $4 \%$ de TOC. (b) Diagrama de Van Krevelen referente às amostras da Formação Itajaí-Açu. HIÍndice de hidrogênio. OI- Índice de oxigênio. 
estão posicionadas no topo da Formação Guarujá, em profundidades superiores a $4.500 \mathrm{~m}$, sendo constituídas por grainstones oolíticos e oolíticos-oncolíticos, depositados em ambiente de alta energia.

Carvalho et al. (1990) identificaram uma coluna de hidrocarbonetos de $255 \mathrm{~m}$, em reservatórios que se apresentam subdivididos em níveis estratigráficos com porosidades variando de $12 \%$ a $24 \%$ e permeabilidades de até $1.400 \mathrm{mD}$. As subdivisões definidas para o reservatório do Campo de Tubarão receberam denominações de B1, B2 e B3 para as porções superior, média e inferior, respectivamente, podendo ser rastreadas em outros poços por meio de marcos elétricos. As zonas de produção mostram características ambientais particulares, constituindo ciclos de shoaling-upward oolíticos. As diferentes composições químicas dos óleos, encontrados em cada uma destas zonas-reservatório, demonstram a eficiência do isolamento ao fluxo entre as diferentes zonas.

Em estudo faciológico da Formação Guarujá, Carvalho (1989) definiu 8 fácies principais, sendo somente 4 volumetricamente importantes. Dentro dos pequenos ciclos de shoaling-upward, as fácies com textura grainstone representam a unidade superior de um ciclo, e aquelas com textura wackestone, a unidade basal. Um ciclo completo consiste, da base para o topo, de wackestone, packstone e grainstone.

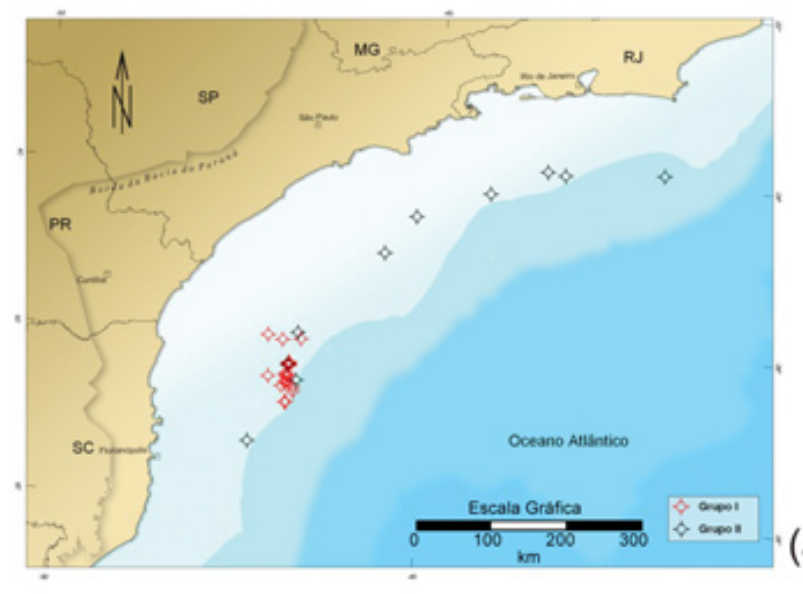

(a)
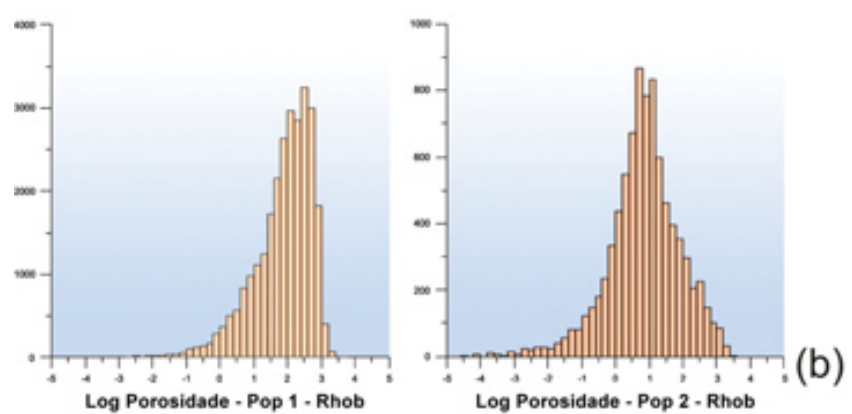

Segundo Carvalho et al. (1990), a preservação da porosidade pode estar associada à diagênese de superfície, que litificou os grãos e retardou a compactação por pressão.

Pela análise detalhada dos dados de porosidade, foi possível distinguir duas populações (I e II) de poços com características porosas bem distintas (Fig. 7). A base de dados formada pelo grupo I apresenta porosidades elevadas, com média de $6,4 \%$ (variação de $4 \%$ a $12 \%$ ). Já o conjunto formado pela população II apresenta valores baixos de porosidade, com média de 2,3\% (variação de 1,3\% a 4,4\%) (Fig. 7b).

Analisando a descrição de amostras de calha, constatou-se que a diferença de porosidade entre as duas populações está intimamente associada à ocorrência de fácies com maior concentração de granulometria média: no grupo I, $16 \%$ das amostras enquandram-se nesta classe, enquanto no grupo II, somente $2 \%$.

A distribuição dos valores de porosidade com a profundidade mostra que porosidades elevadas ocorrem até mesmo em profundidades elevadas de $5000 \mathrm{~m}$, observando-se, a partir daí, um declínio mais acentuado da porosidade (Fig. 7c).

\section{Reservatórios Siliciclásticos}

ARENITOS DO MEMBRO ILHABELA Os reservatórios turbidíticos do Membro Ilhabela ocorrem interca-

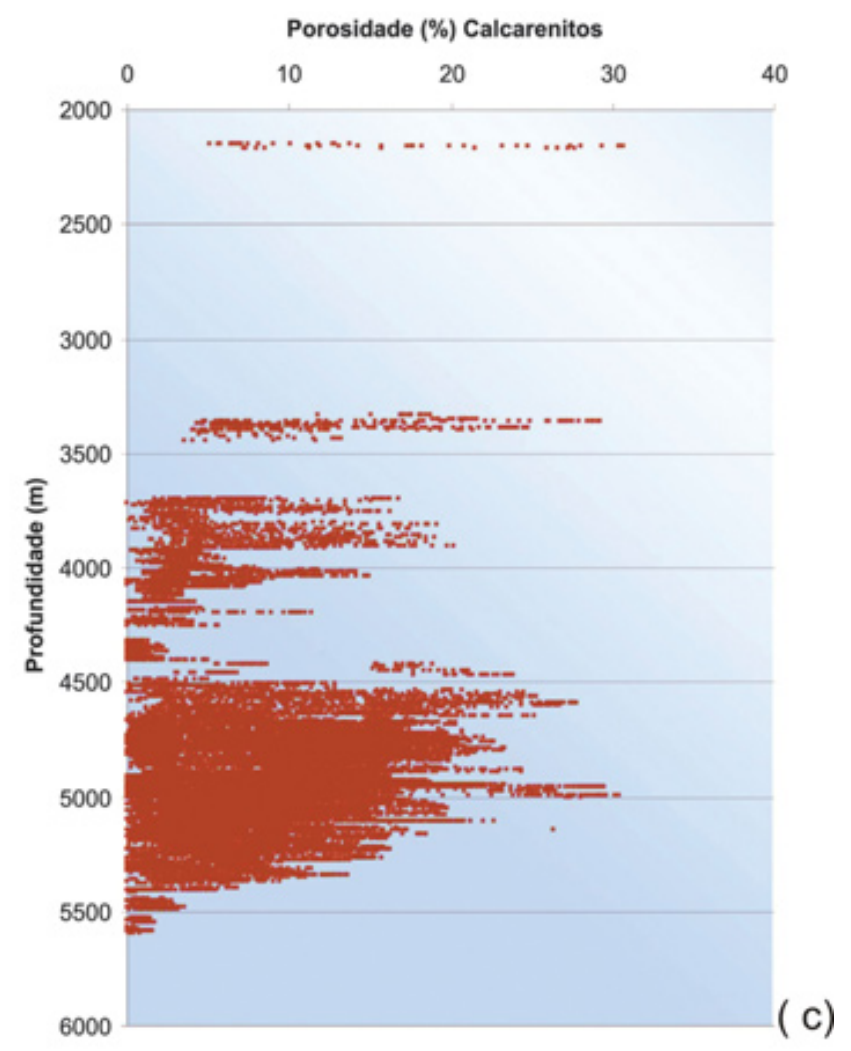

Figura 7 - Conjunto de poços analisados para a caracterização do padrão de porosidade para os reservatórios crabonáticos da Formação Guarujá. (a) Mapa de localização dos poços analisados. (b) Histogramas de porosidade representados por logarítmo neperiano da porosidade obtida de perfis de densidade, referentes aos grupos de poços I e II, da Formação Guarujá. (c) Distribuição de porosidade com profundidade, de calcarenitos da Formação Guarujá. Porosidade calculada a partir de perfis de densidade (FDC). 
lados com pelitos de água profunda da Formação ItajaíAçu. A espessura porosa dos arenitos nesta unidade é superior a $100 \mathrm{~m}$, contendo até 10 zonas porosas. Esta análise foi efetuada com 15 poços, utilizando-se perfil sônico e de densidade. O critério adotado para definir a espessura foi a predominância de valores de porosidade calculada superiores a $12 \%$. Já na análise da distribuição das porosidades dos arenitos turbidíticos, foram utilizados somente 10 poços que possuíam perfil densidade. Os valores obtidos apresentam distribuição normal, com bimodalidade, cujos valores mais altos (20 a $24 \%$ ) provêm de um único poço (BSS-83), fornecendo valor médio de $20,3 \%$. No entanto, se excluído este poço anômalo, a média cai para $12,5 \%$ (Fig. 8).

O comportamento da porosidade com a profundidade é semelhante ao que ocorre com todos os sedimentos submetidos a soterramento, isto é, progressiva diminuição de porosidade. Na figura $8 \mathrm{~b}$, observa-se que ocorre uma grande concentração de valores entre $10 \mathrm{e}$ $15 \%$, em profundidades entre 4500 e $5000 \mathrm{~m}$.

$\mathrm{Na}$ análise de testemunhos efetuada em dois poços na região do Campo de Merluza, por Sombra et al. (1990), foram reconhecidos, como principal litofáciesreservatório, os arenitos maciços de granulometria fina a grossa e seleção pobre a moderada do Membro Ilhabela. Petrograficamente, esses arenitos apresentam arcabouço constituído predominantemente por quartzo $(50-60 \%)$, feldspatos (20-25\%) e litoclastos de vulcânicas (10\%), podendo ser classificados como arcóseos ou arcóseos líticos. Um aspecto marcante destes arenitos é o desenvolvimento de franjas de clorita em torno de grãos. Esta cimentação é eodiagenética, associada à alteração de litoclastos vulcânicos em ambiente marinho, fora da influência de água meteórica. Localmente, ocorre a precipitação de calcita poiquilotópica pré-cimentação da clorita. Para Sombra et al. (1990), a precipitação da clorita favoreceu a preservação da porosidade, algo em torno de 4 a $9 \%$, resultando em porosidades medidas de $21 \%$ a $4700 \mathrm{~m}$ (SPS-20) e de $16 \%$ a 4900m (SPS-25).

A distribuição espacial dos dois principais reservatórios da Bacia de Santos está ilustrada na figura 9. Em função das características porosas dos carbonatos da Formação Guarujá, esses reservatórios estão restritos à porção sul da bacia, enquanto os arenitos Ilhabela concentram-se no eixo central da Bacia de Santos.

\section{ARENITOS DO CRETÁCEO SUPERIOR E EOCE-}

$N O$ Outras unidades litoestratigráficas também constituem rochas-reservatório siliciclásticas, podendo-se destacar os arenitos das Formação Santos/Juréia, além de arenitos turbidíticos de idade campaniana-maastrichtiana e eocênica. Estes turbiditos ocorrem principalmente na porção central e norte da bacia, como é o caso dos poços 1SPS-032 (Cretáceo Superior) e 1BSS-069 (Eoceno).

O gráfico da figura 10 ilustra a relação Porosidade versus Profundidade, obtida a partir do perfil densidade de 10 poços, onde se observa a mesma tendência de diminuição da porosidade com a profundidade apresentada nas figuras $7 \mathrm{c}$ e 8 b. Porém, constata-se que mesmo em profundidades superiores a $4000 \mathrm{~m}$ ocorrem
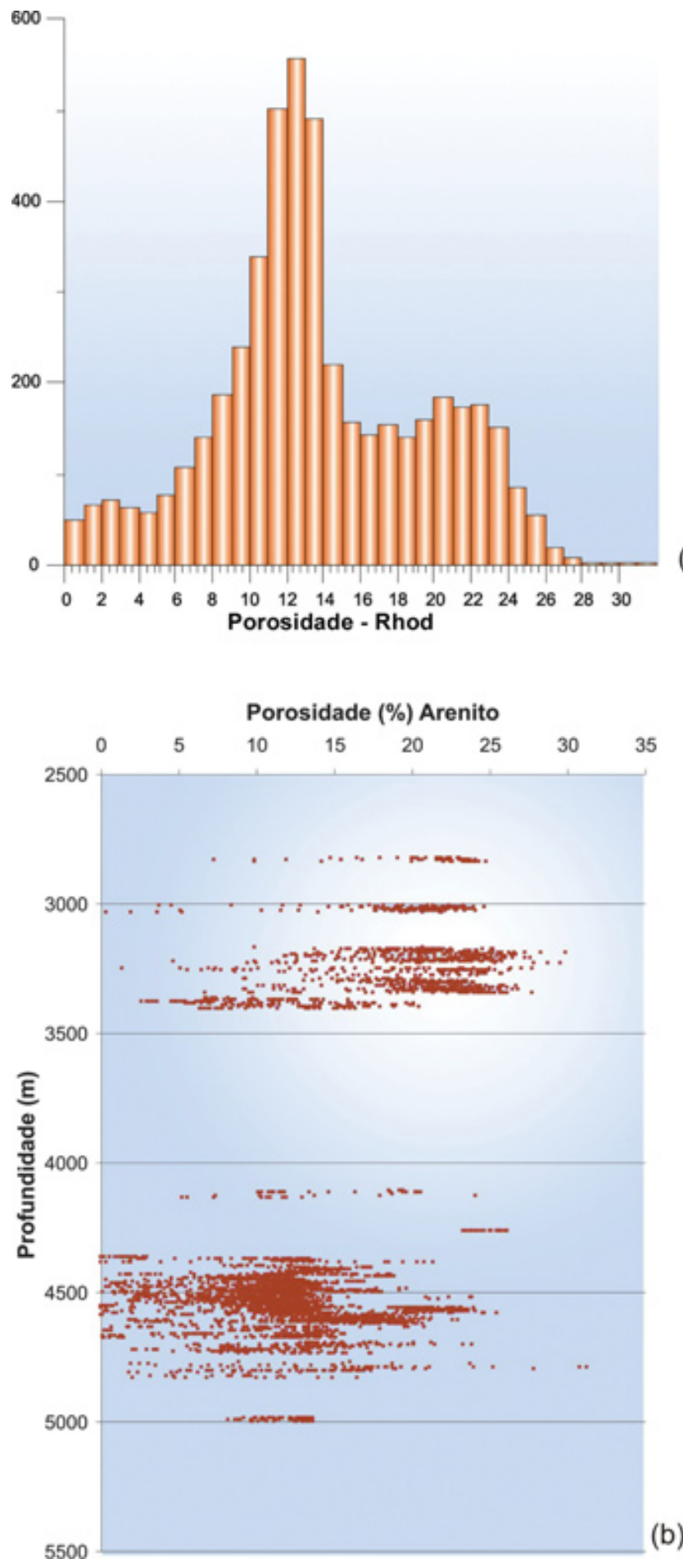

Figura 8 - Gráficos resultantes da análise de porosidade em poços que atingiram os reservatórios do Membro Ilhabela. (a) Distribuição dos valores de porosidade (\%) dos arenitos turbiditicos do Membro Ilhabela. Os altos valores provêm de um único poço (BSS-83). (b) Distribuição de porosidade com profundidade, de arenitos turbiditicos Ilhabela. Porosidade calculada a partir de perfis de densidade (FDC).

intervalos com porosidade superior a $15 \%$.

TRAPAS E SELOS De maneira geral, os selos para as diversas rochas reservatório da Bacia de Santos são constituídos por pelitos e calcilutitos intercalados aos 
próprios reservatórios.

No caso da Formação Guarujá, as rochas selantes são tanto os calcilutitos intercalados aos calcarenitos porosos, que formam os ciclos de coarsening-upward, quanto, na porção mais superior, os calcilutitos e pelitos da Formação Itanhaém. Considerando os reservatórios siliciclásticos, as rochas selantes são os pelitos intercalados aos arenitos das formações Itajaí-Açu, Santos/ Juréia e Marambaia.

Para as rochas-reservatório da seção rifte, podese considerar a seqüência evaporítica (Formação Ariri) como um ótimo selo, bem como a variação litológica das unidades da própria seção rifte, que contêm intercalações de sedimentos pelíticos.

As principais acumulações da bacia mostram trapas de caráter estrutural e misto. O inter-relacionamento entre o aporte sedimentar e o imenso volume de evaporitos depositados durante o Aptiano teve papel fundamental na geração de trapas ligadas à halocinese. A grande maioria das armadilhas geradas está associada a domos ou diápiros salinos. Assim sendo, mesmo quando são observadas feições estratigráficas passíveis de armazenamento, estas encontram-se deformadas pela halocinese, gerando trapas mistas. O período de formação das trapas ligadas à halocinese estende-se desde o Neo-Albiano, em águas rasas, até o Oligoceno, na região de águas profundas.

Como já mencionado anteriormente, a intensa movimentação halocinética transformou armadilhas eminentemente estratigráficas em mistas. No entanto, não se deve descartar a importância destas trapas estratigráficas, que podem ocorrer principalmente nas unidades mais recentes, principalmente no Terciário e, em menor grau, no Maastrichtiano.

As trapas mais comuns em regiões com intensa halocinese, que deve ser considerada para a região de águas profundas, é o acunhamento de corpos arenosos contra a parede de domos e diápiros salinos (pinch-out).

Trapas associadas a altos estruturais da seção rifte constituem excelentes concentradores de hidrocarbonetos, como é o caso das recentes descobertas da Petrobras em águas ultra-profundas da Bacia de Santos (Campo de Tupi).

MATURIDADE TERMAL Modelagens numéricas multidimensionais da maturidade termal da Bacia de Santos apontam o intervalo de 70 a 90 Ma como o pico máximo da gera e expulsão de hidrocarbonetos provindos da Formação Guaratiba (fase sin-rifte III). Porém, pela grande extensão geográfica, as rochas da Formação Guaratiba não entraram na janela de geração de óleo de maneira uniforme, podendo a geração ter-se estendido até o Paleoceno (Fig. 11).

Da análise dos mapas de maturação para a seção rifte (Figs. 12a e 12b), conclui-se que a geração teve início no Neo-Albiano/Eo-Cenomaniano, em calha alongada de direção NE, que com o passar do tempo foi se estendendo tanto em sentido às águas rasas como às águas profundas. Já ao final do Cretáceo, a área com potencial de geração de hidrocarbonetos ocupava uma

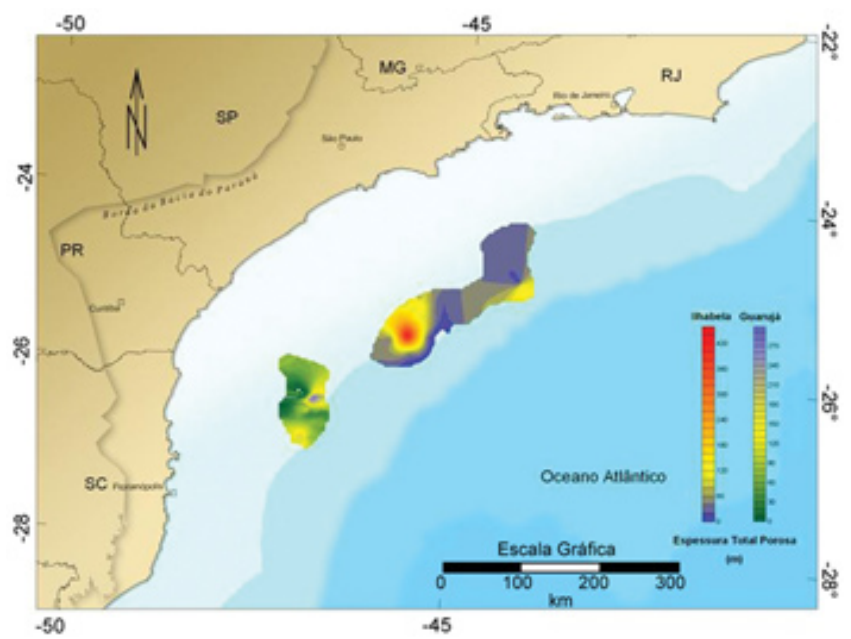

Figura 9 - Mapa de espessura total porosa dos reservatórios turbidíticos do Membro Ilhabela e dos carbonatos de água rasa da Formação Guarujá. Linhas de contorno baseadas em dados de poços.

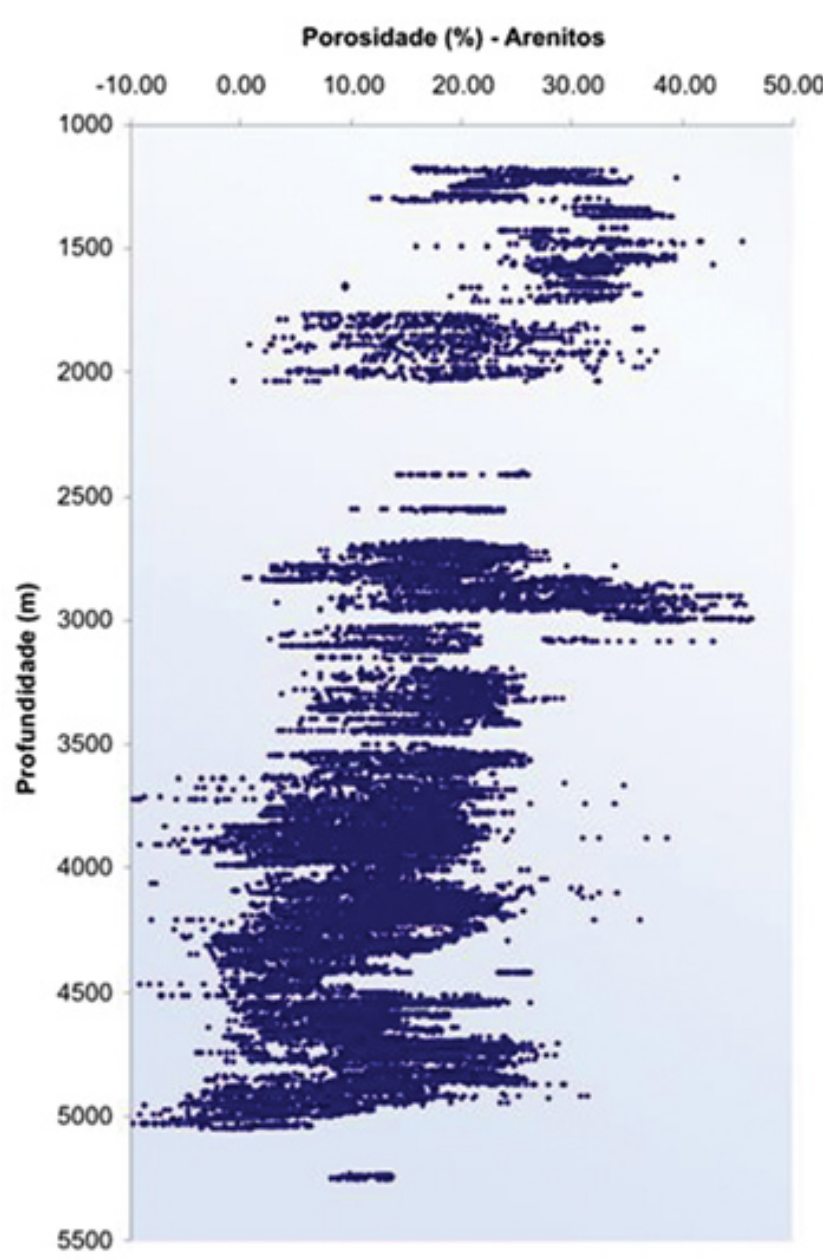

Figura 10 - Distribuição de porosidade com profundidade para arenitos não pertencentes ao Membro Ilhabela. Porosidade calculada a partir de perfis de densidade. 

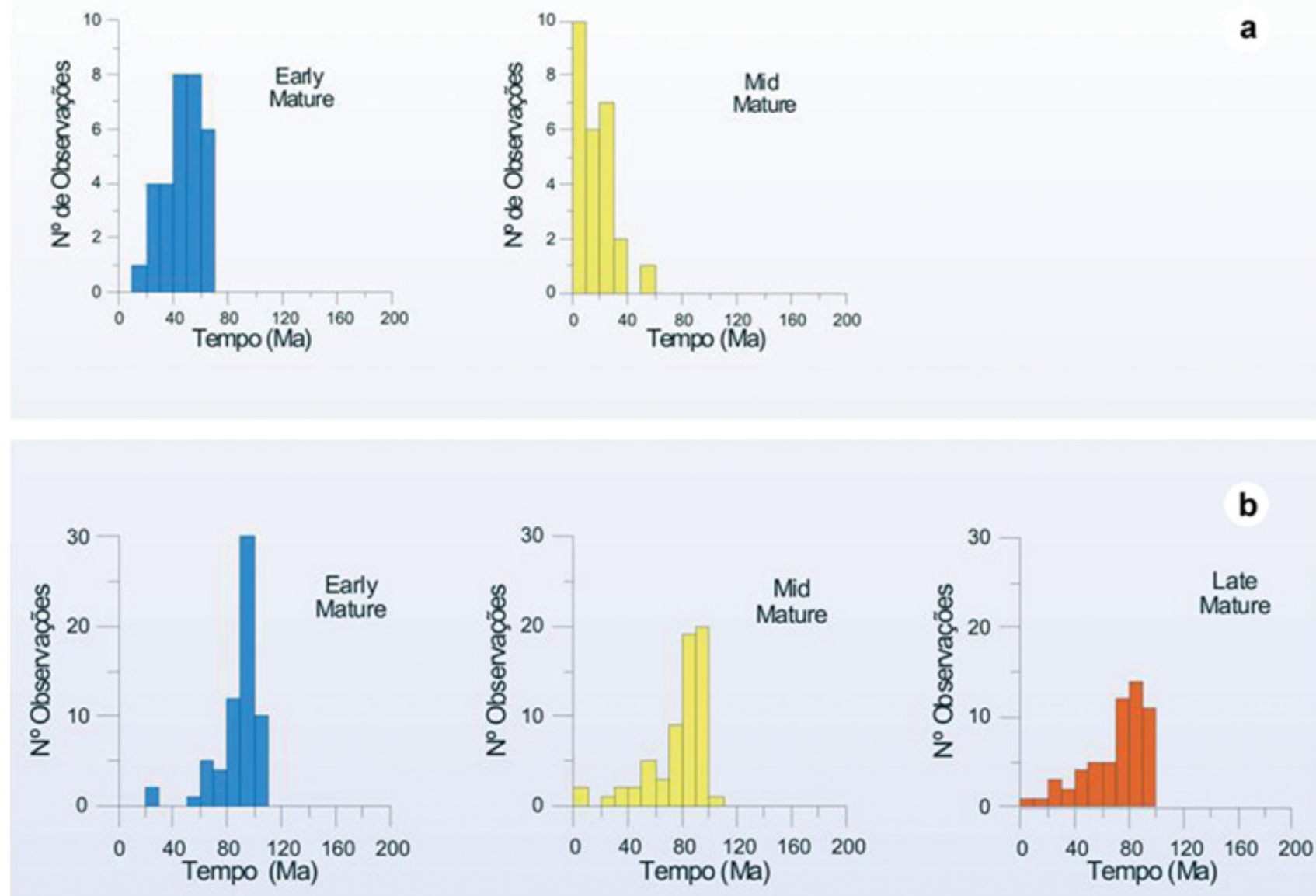

Figura 11 - Distribuição temporal da maturação. a) gerador Itajaí-Açu. b) gerador Guaratiba. Early Mature corresponde ao estágio inicial de maturação $(0.5<$ Ro\% $<0.7)$. Mid Mature corresponde ao pico de maturação $(0.7<$ Ro\% 1.0). Late Mature corresponde à fase final de geração $(1.0<$ Ro\% $<1.3)$.

parte significativa da bacia, sendo coincidente com as maiores espessuras da seqüência pós-rifte.

Por outro lado, considerando a porção basal da Formação Itajaí-Açu (seqüência H4-H5), verifica-se que permaneceu no início da janela de maturação térmica durante boa parte da história evolutiva da bacia (Fig. 11). Contudo, a partir da Oligoceno, algumas áreas mostram maior maturação. Com relação à expulsão, a modelagem 2D indica que esta ocorreu nas porções central e sul da bacia, em baixos estruturais ocasionados pela halocinese.

MIGRAÇÃO E ACUMULAÇÃO Os processos de migração e acumulação de hidrocarbonetos na Bacia de Santos encontram-se intimamente ligados à dinâmica da seqüência evaporítica que, por sua baixíssima permeabilidade, atuou e atua como importante condicionante ao fluxo dos hidrocarbonetos gerados na seção rifte. Estes hidrocarbonetos migraram até o contato basal da seqüência sedimentar pré-aptiana, utilizando esta como camada carreadora (carrier-bed). A geometria da base do sal direcionou o fluxo criando várias redes de drenagem e vias preferenciais até áreas onde existissem janelas na seqüência evaporítica, ou onde esta possuísse uma es- pessura adelgaçada $(<200 \mathrm{~m})$, permitindo que os hidrocarbonetos migrassem para cima, em sentido à seqüência pós-evaporítica. Uma vez vencidas as barreiras impostas pelos evaporitos, o fluxo se concentrou nas falhas distensionais lístricas associadas aos domos e diápiros de sal, ou em falhas de transferência, até as armadilhas.

Neste processo, o imenso aporte sedimentar ocorrido entre o Campaniano e o Maastrichtiano, que formou as grandes cunhas clásticas na Calha Central, foi responsável pela criação de uma grande janela de sal, originada pela expulsão dos evaporitos da Formação Ariri em direção às águas profundas.

Outro fator importante no direcionamento do fluxo de hidrocarbonetos gerados na seção rifte foi a atuação das falhas da própria fase rifte, que tanto compartimentaram a sedimentação desta idade, como também focalizaram a migração para os altos estruturais.

No caso dos hidrocarbonetos gerados na Formação Itajaí-Açu, estes migraram preferencialmente pelas falhas lístricas ou de transferência originadas pela halocinese.

As modelagens realizadas indicam que a fase de geração e expulsão de hidrocarbonetos da seção rifte iniciou-se por volta de $100 \mathrm{Ma}$., tendo seu pico entre 90 

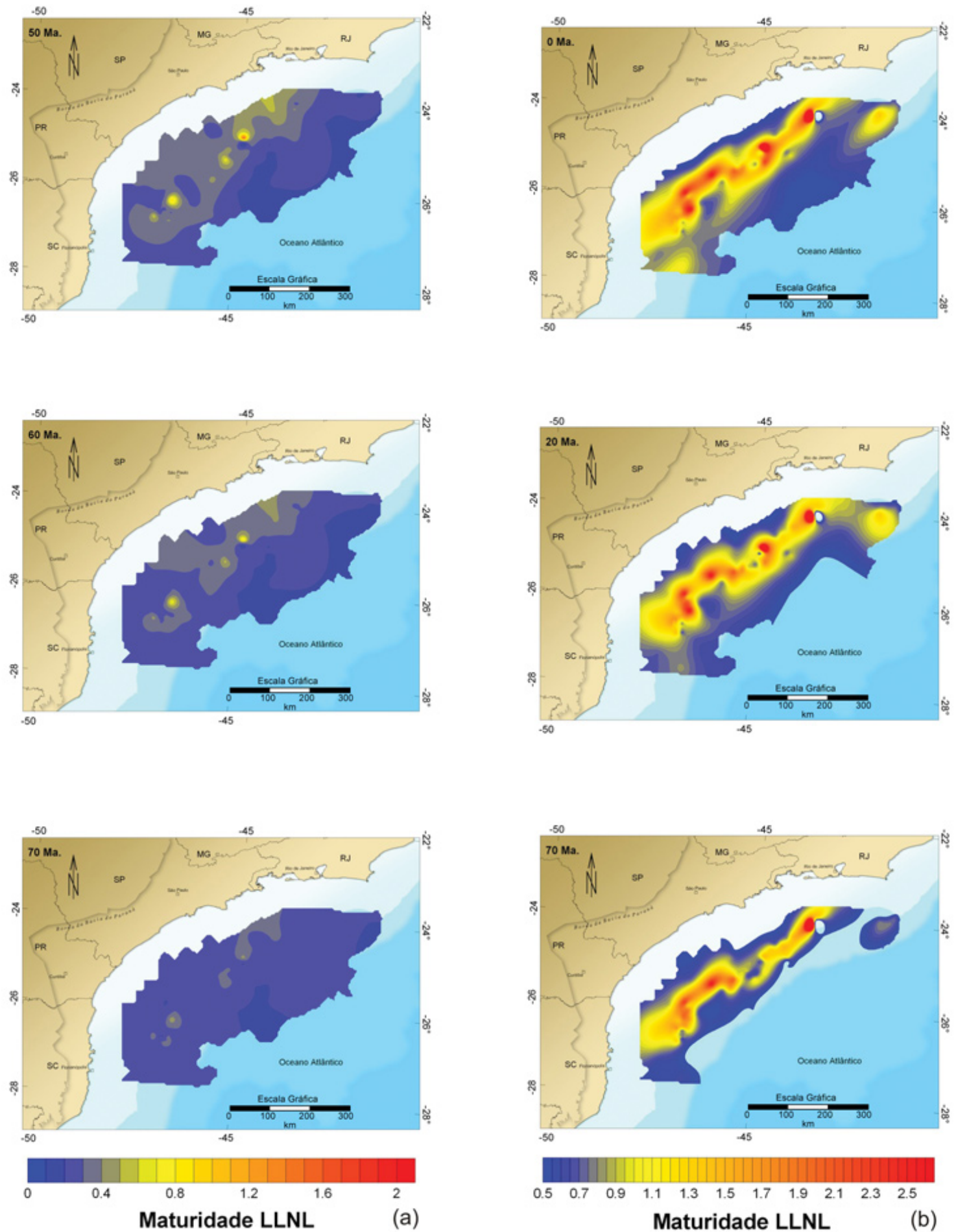

Maturidade LLNL

(b)

Figura 12 - Mapas temporais de maturidade da rocha geradora obtidos a partir de modelagens numéricas. (a) Mapas de maturidade da Formação Itajai-Açu. (b) Mapas de maturidade da Formação Guaratiba.

e 70 Ma., estendendo-se até o Eoceno, aí já com menor intensidade. Desta forma, tais condições viabilizaram o trapeamento em todos os reservatórios citados, tanto os carbonatos da Formação Guarujá quanto os arenitos do Membro Ilhabela (Formação Itajaí-Açu), do NeoCretáceo (Formação Juréia) e do Eoceno (Formação
Marambaia) (Fig. 13a).

Por outro lado, para as rochas geradoras da porção basal da Formação Itajaí-Açu, cujas modelagens indicam geração a partir do Maastrichitiano, verifica-se a existência de sincronismo para todos os reservatórios da seção pós-evaporítica (Fig. 13b). 


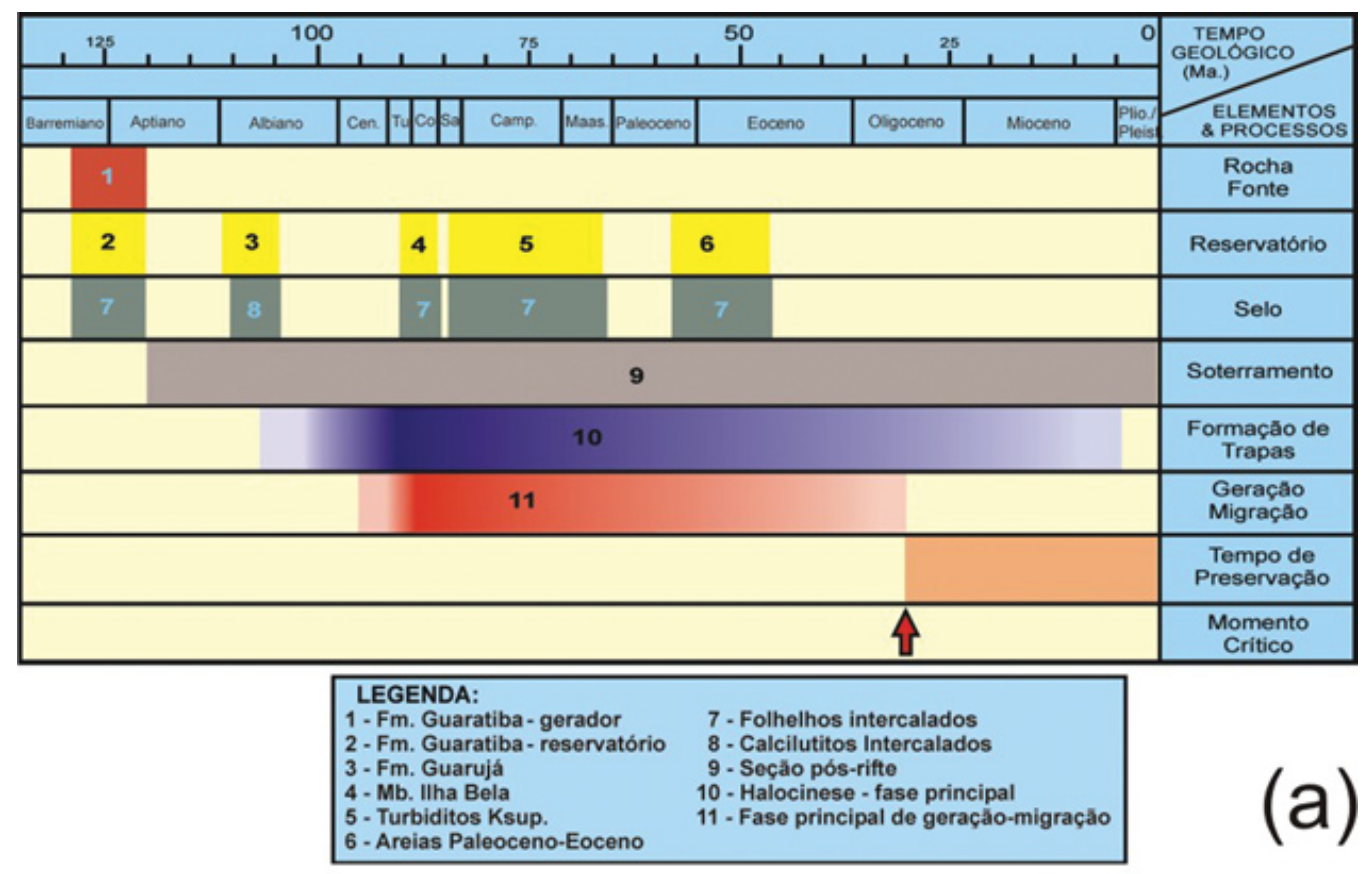

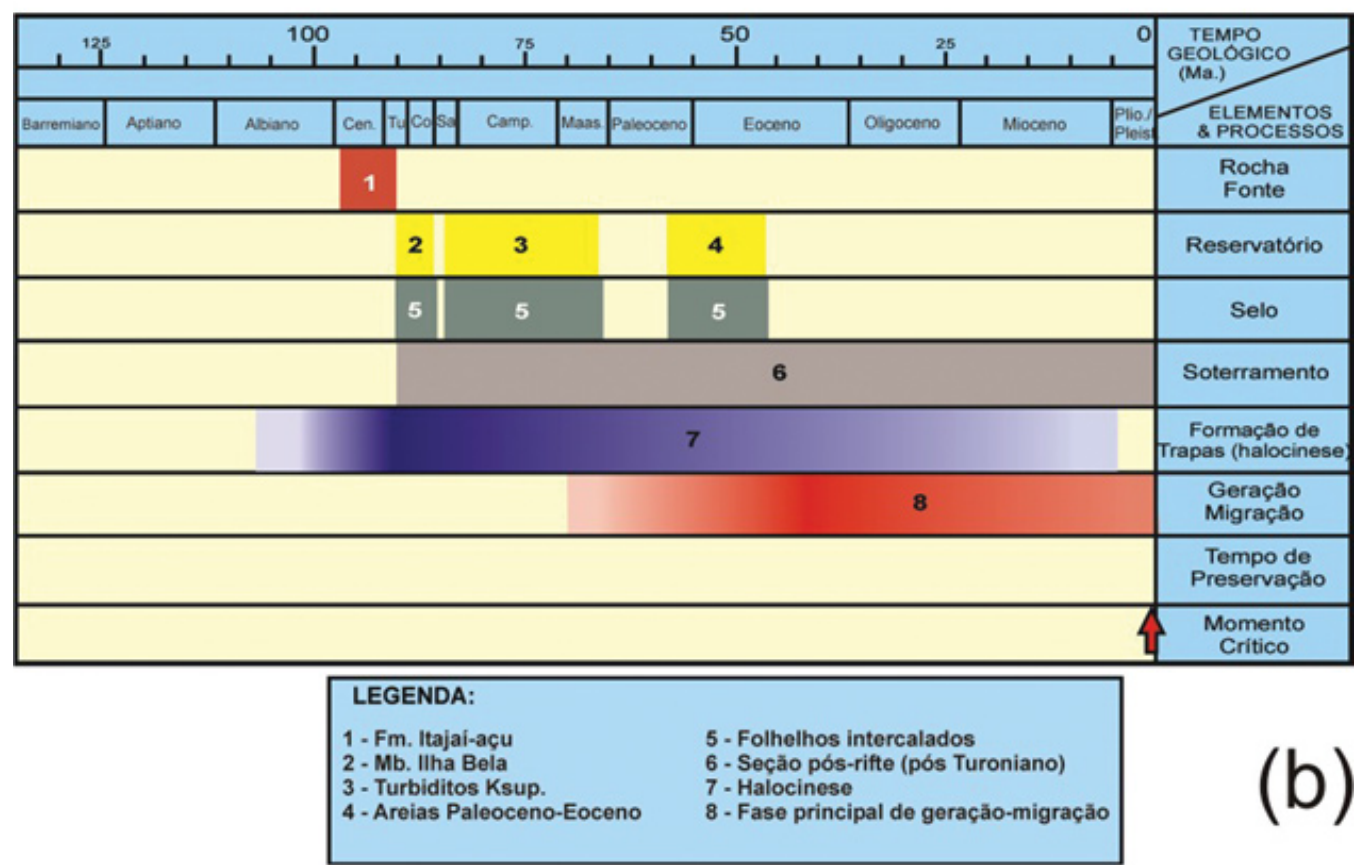

Figura 13 - Cartas de eventos dos principais sistemas petroliferos da Bacia de Santos. (a) Carta de elementos essenciais e processos do Sistema Petrolifero Guaratiba - Guarujá (!). (b) Carta de elementos essenciais e processos do Sistema Petrolifero Itajai-Açu - Ilhabela (.).

MODELOS DE ACUMULAÇ̃̃O DE HIDROCARBONETOS NA BACIA DE SANTOS A exploração petrolífera na Bacia de Santos passou por várias fases, desde a perfuração do primeiro poço em 1971, no litoral do Estado do Paraná. Desde então, vários modelos de acumulação de petróleo surgiram e foram perseguidos em mais de 190 poços perfurados até hoje, que resultaram na descoberta de 17 campos de óleo, gás e conden- sado, além de várias acumulações sub-comerciais.

A seguir são descritos os principais modelos de acumulação existentes na Bacia de Santos, que se concentram essencialmente na seção pós-evaporítica. Estes modelos de acumulação devem ser considerados modelos complementares (Magoon \& Beaumont 1999), pois estão relacionados a um sistema petrolífero específico, ou seja, o sistema Guaratiba - Guaruja (!). 
Modelo de Acumulação da Seção Rifte A seção rifte da Bacia de Santos não havia sido testada com foco exploratório até início do século 21, quando a Petrobras fez as primeiras incursões exploratórias à seção rifte em águas ultra-profundas e obteve sucesso. O cenário perdurou durante muito tempo pela falta de tecnologia de perfuração em águas ultra-profundas, além de uma espessa camada de sal (cerca de $2000 \mathrm{~m}$ de espessura), sobrejacente à seção rifte, que dificultava a construção de poços. Até então, haviam sido perfurados somente três poços que atingiram a seção rifte nas porções mais proximais, onde foram observados arenitos avermelhados e conglomerados de borda de falha.

As informações obtidas de interpretações sísmicas apontavam para um modelo semelhante à Bacia de Campos, com a ocorrência de altos estruturais do embasamento controlando a acumulação de hidrocarbonetos em reservatórios carbonáticos, siliciclásticos e até mesmo em rochas vulcânicas fraturadas, como no campo de Badejo.

Modelos análogos à Bacia de Campos se confirmaram com as descobertas dos campos de Tupi e Júpiter, cujas acumulações gigantes (da ordem de 6 bilhões de barris) ocorrem em altos estruturais da seção rifte, em reservatórios siliciclásticos e carbonáticos (Andar Alagoas). A geração ocorre nos baixos estruturais da mesma seção e a migração se dá por carrier-bed até o ápice das estruturas, as quais apresentam excelente geometria de fechamento (Fig. 14a).

Modelo de Acumulação da Formação Guarujá (Rochas Carbonáticas Albianas) A primeira acumulação descoberta na Formação Guarujá foi o Campo de Tubarão, em 1988, abrindo uma nova perspectiva para a região sul da Bacia de Santos. Os reservatórios são constituídos de calcarenitos oolíticos de variada gama textural, essencialmente grainstones, depositados em ambiente de águas rasas. Possivelmente, durante a deposição destes carbonatos, já havia um princípio de halocinese, o que garantiu uma situação mais elevada às porções situadas no ápice dos primeiros domos. De qualquer maneira, a continuidade da deformação acabou por compartimentar a Formação Guarujá, criando trapas essencialmente estruturais, ou ainda mistas. $\mathrm{O}$ selo para esta unidade é dado pelos calcilutitos intercalados à própria Formação Guarujá e, em alguns casos, pelos pelitos da Formação Itanhaém.

A figura $14 \mathrm{~b}$ mostra o modelo de acumulação dos campos de Tubarão e Caravela, com geração a partir da seção rifte (Formação Guaratiba). Pode-se prever também a possibilidade de acumulação de hidrocarbonetos gerados a partir da própria Formação Guarujá (Albiano Médio-Inferior), ou até mesmo em calhas muito profundas onde exista a deposição da seção inferior da Formação Itajaí-Açu (Seqüência H4-H5 - Fig. 2).

Modelo de Acumulação do Membro Ilhabela (Arenitos Turbidíticos do Neo-Turoniano - Eo-Santoniano) Os arenitos turbidíticos do Membro Ilhabela (Formação Itajaí-Açu) possuem idade neo-turoniana a eo-santoniana e deveriam apresentar, originariamente, situações de trapeamento estratigráfico por acunhamento de corpos arenosos em sentido contrário ao mergulho da bacia (pinch-out). No entanto, a intensa atividade halocinética da bacia deformou estes estratos, falhando-os ou dobrando-os, compondo desta forma trapas essencialmente mistas ou mesmo, em alguns casos, trapas estruturais. O selo destas camadas é fornecido por pelitos intercalados na mesma seqüência estratigráfica. Adota-se como modelo para este tipo de acumulação no Campo de Merluza, primeira descoberta de hidrocarbonetos ocorrida em 1984 (Fig. 14c).

Modelo de Acumulação do Senoniano (Turbiditos do Maastrichtiano - Campaniano) Os reservatórios turbidíticos de idade maastrichtiana-campaniana, associados às imensas cunhas clásticas depositadas nas porções central e norte da Bacia de Santos são os principais alvos deste modelo de acumulação. Na coluna estratigráfica de Pereira \& Feijó (1994), estes arenitos são denominados Membro Ilhabela, porém, por serem depositados nas porções frontais das cunhas clásticas santonianas e maastrichtianas, optou-se por uma denominação distinta - arenitos turbidíticos do Senoniano.

As trapas são eminentemente estruturais podendo, em alguns casos, ser interpretadas como mistas e/ou estratigráficas. As rochas selantes são pelitos da própria Formação Itajaí-Açu, intercalados aos reservatórios (Fig. 14d).

Modelo de Acumulação da Formação Marambaia (Arenitos Turbidíticos Terciários) Os reservatórios do modelo de acumulação Marambaia são constituídos de arenitos turbidíticos de idade terciária, que se encontram imersos nos pelitos de água profunda da Formação Marambaia. À semelhança da Bacia de Campos (Membro Carapebus), estes arenitos estariam associados à remobilização de areias depositadas na plataforma, principalmente devido a quedas do nível eustático do mar. Os próprios pelitos da Formação Marambaia selam os arenitos turbidíticos e as trapas podem ser tanto estratigráficas quanto mistas, dependendo do maior ou menor envolvimento dos estratos com a halocinese (Fig. 14e).

$\mathrm{Na}$ porção norte da bacia, existem corpos turbidíticos de idade eocênica, que encontram-se associados a deltas de borda de plataforma, muito bem desenvolvidos. Estes turbiditos são responsáveis por uma notável acumulação na área do poço 1BSS-069, onde se estima um volume in place da ordem de 500 milhões de barris de óleo. Todavia, o óleo encontrado nesta acumulação é pesado, com grau API da ordem de $15^{\circ}$, revelando provável processo de biodegradação.

Já na porção sul da bacia, ocorre um grande espessamento da seção terciária inferior, constituída por sistemas deposicionais de água profunda. Esta seção não foi amostrada por poços, sendo desconhecidas suas características como reservatório. Por outro lado, a ausência de processos halocinéticos mais intensos pode desfavorecer a migração para estes possíveis reservatórios. 

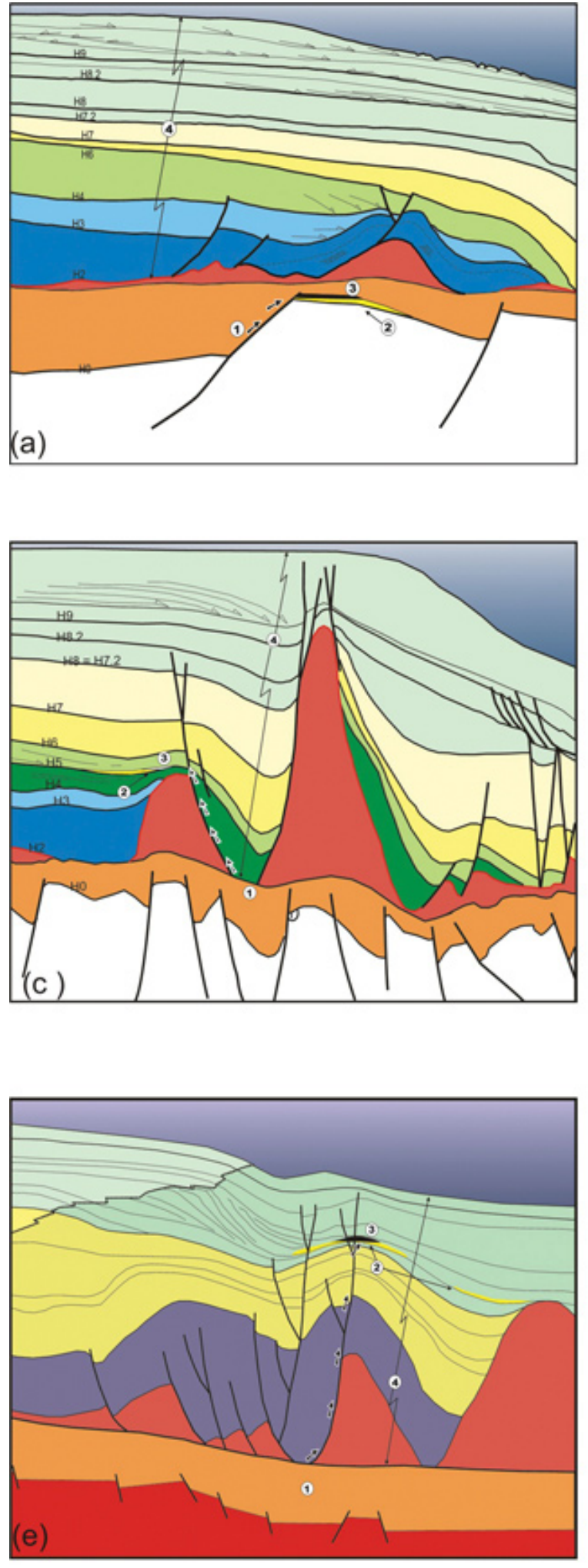
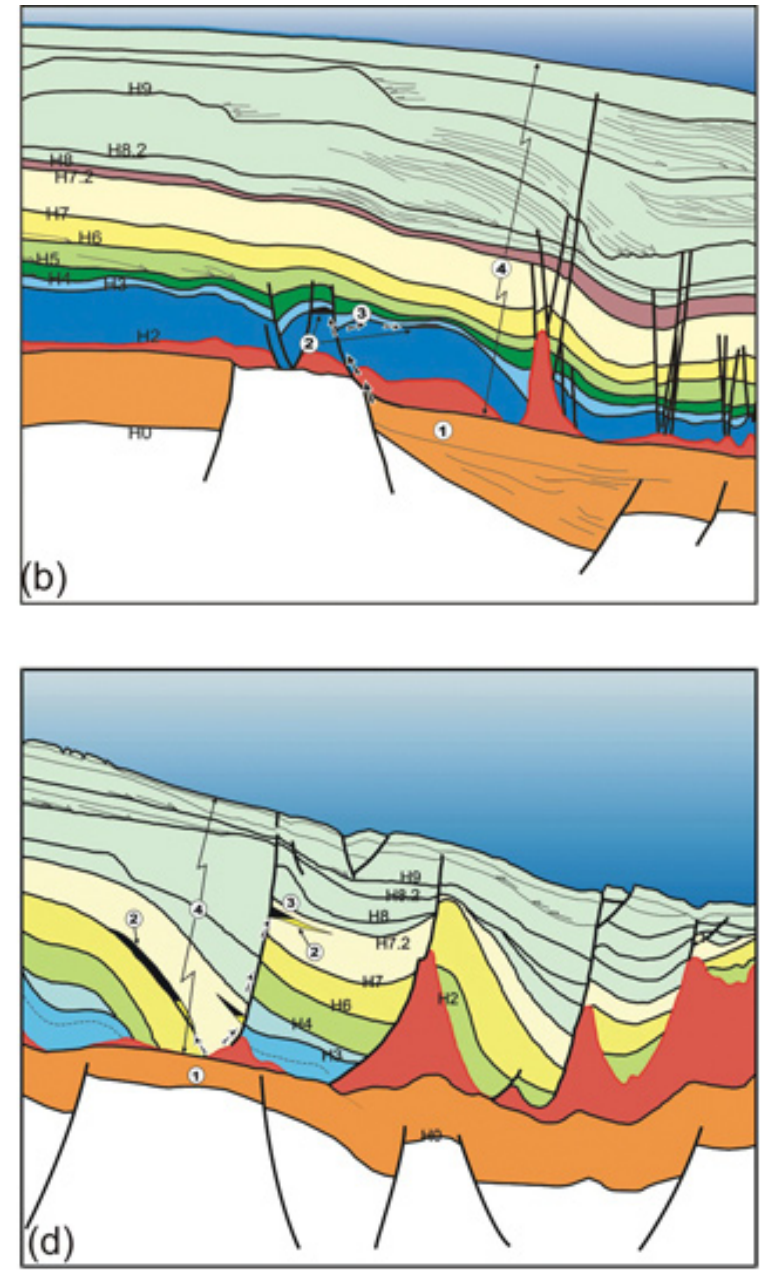

\section{Elementos do sistema petrolífero}

(a) 1 - Gerador: Folhelhos da Formação Guaratiba; 2 Reservatório: Coquinas da Formação Guaratiba; 3 - Selo: Pelitos intraformacionais; 4-Soterramento.

(b) 1 - Gerador: Folhelhos da Formação Guaratiba; 2 Reservatório: Calcarenitos da Formação Guarujá; 3 - Selo: Calcilutitos intraformacionais e Formação Itanhaem; 4 Soterramento.

(c) 1 - Gerador: Folhelhos da Formação Guaratiba; 2 Reservatório: Arenitos do Membro Ilhabela; 3 - Selo intraformacional: Formação Itajai-Açu; 4 -Soterramento.

(d) 1 - Gerador: Folhelhos da Formação Guaratiba; 2 Reservatório: Arenitos turbidíticos campanianos e maastrichitianos da Formação Itajai-Açu; 3 - Selo: Pelitos intraformacionais; 4 -Soterramento.

(e) 1 - Gerador: Folhelhos da Formação Guaratiba; 2 Reservatório: Arenitos turbiditicos da Formação Marambaia; 3 - Selo: Pelitos intraformacionais; 4 Soterramento.

Figura 14 - Seções geológicas esquemáticas dos principais modelos de acumulações de petróleo na Bacia de Santos. (a) Modelo de acumulação da seção rifte. (b) Modelo de acumulação para Formação Guarujá. (c) Modelo de acumulação para o Membro Ilhabela. (d) Modelo de acumulação do Senoniano. (e) Modelo de acumulação para a Formação Marambaia.

CONSIDERAÇÕES FINAIS O estudo geológico integrado da Bacia de Santos, escopo deste artigo, possibilitou novas interpretações para os sistemas petrolí- feros da bacia. Esse estudo promoveu o reconhecimento regional das principais discordâncias estratigráficas, a identificação e a caracterização das principais feições 
estruturais, principalmente aquelas geradas pela halocinese, e a modelagem da evolução geoquímica, contemplando maturidade, geração e expulsão de hidrocarbonetos. A integração dessas informações permitiu a elaboração de cenários promissores à acumulação de hidrocarbonetos na bacia.

$\mathrm{Na}$ Bacia de Santos foram identificados dois sistemas petrolíferos: Guaratiba-Guarujá (!) e ItajaíAçu-Ilhabela (!), cujas rochas geradoras apresentam características de deposição em ambientes lacustres e marinhos, respectivamente. A Formação Guaratiba é considerada a principal rocha geradora da bacia e, por meio de modelagens numéricas de maturidade, estimou-se o ápice da geração no Maastrichtiano, resultando num sincronismo perfeito com os demais elementos essenciais à acumulação de petróleo.

Uma vasta quantidade de reservatórios pode ser encontrada em toda a seção sedimentar da bacia, desde a seqüência rifte, com os depósitos siliciclásticos e carbonáticos, passando pela grande plataforma carbonática oolítica da Formação Guarujá, sobreposta por depósitos turbidíticos do Membro Ilhabela. Os de- pósitos turbidíticos também podem constituir importantes reservatórios na Formação Santos/Juréia, bem como na Formação Marambaia. É valido ressaltar que todos esses reservatórios são portadores de hidrocarbonetos e, em alguns casos, constituem campos economicamente explotáveis.

Uma importante fronteira exploratória foi ultrapassada nos últimos anos, com a perfuração de poços que atingiram a seção rifte em águas profundas, a qual só se conhecia em águas rasas. Grandes acumulações foram descobertas na seqüência sin-rifte III (Andar Alagoas), em altos estruturais concentradores da migração de hidrocarbonetos provindos das porções mais profundas.

Agradecimentos Os autores agradecem o apoio recebido da Agência Nacional de Petróleo (ANP), da Fundação para o Desenvolvimento da UNESP (FUNDUNESP) e do Laboratório de Estudos de Bacias (LEBAC/UNESP). Este trabalho contou com a contribuição de vários pesquisadores que atuaram no convênio ANP/FUNDUNESP (2001-2006).

\section{Referências}

ANP 2003. Interpretação e mapeamento dos sistemas petrolíferos da Bacia de Santos. Relatório ANP/FUNDUNESP, Tomo 1:1-170.

Arai M. 1988. Geochemical Reconnaissance of the Mid-Cretaceous anoxic event in the Santos Basin, Brazil. Revista Bras. de Geociências, 18:273-282.

Azevedo J.M.F. 1991. Integração entre o preenchimento Sedimentar cenozóico das bacias de Campos e Santos e a evolução tectônica e geomorfológica das áreas continentais adjacentes. Dissertação de Mestrado, Departamento de Geologia, Universidade Federal de Ouro Preto, $150 \mathrm{p}$.

Bigarella J.J. \& Andrade G.O. 1965. Contribution to the study of the Brazilian quaternary. Geological Society Special Publication, 84:433-451.

Brandão J.A.S.L. \& Guardado L.R. 1998. The petroleum exploration in Brazil. Searching for oil and gas in the lands of giants, 1:2-14.

Carvalho M.D. 1989. Microfacies, modelo deposicional e evolução da plataforma carbonática do Eo/Mesoalbiano da Bacia de Santos. Dissertação de Mestrado, Instituto de Geociências, Universidade Federal do Rio de Janeiro, $110 \mathrm{p}$.

Carvalho M.D., Praça U.M., Junior J.J.M., Spadini A.R. 1990. Reservatórios carbonáticos profundos do eo/mesoalbiano da Bacia de Santos. Revista de Geociências da Petrobrás, 4:429-450.

Chang H.K., Kowsmanm R.O., Figueiredo A.M.F. 1990. Novos conceitos sobre o desenvolvimento das bacias marginais do leste brasileiro. In: Raja Gabaglia G.P. \& Milani E.J. (eds) Origem e Evolução de bacias sedimentares. Petrobrás, p.269-289.

Chang H.K., Kowsmann R.O., Figueredo A.M.F., Bender A.A. 1992. Tectonics and stratigraphy of the East Brazil rift system: an overview. Tectonophysics, 213:97-138.

Cobbold P.R., Meisling K.E., Mount V.S. 2001. Reactivation of an obliquely-rifted margin, Campos and Santos basins, southeastern Brazil. AAPG Bulletin, 85:1925-1944.

Corrêa F.S., Rostirolla S.P., Chang H.K. 2007. Arcabouço estrutural e evolução da propagação da fase rifte nas Bacia de Campos e Santos. In: SBG, Simpósio Nacional de Estudis Tectônicos, 11 e V International Symposium on Tectonics of the SBG, 5, atas, v.1, p.54-57.

Demercian L.S., Szatmari P., Cobbold P.R. 1993. Style and pattern of salt diapirs due to thin-skinned gravitational gliding, Campos and Santos Basin, offshore Brazil. Tectonophysics, 228:393-433.

Demercian L.S. 1996. A halocinese na evolução do sul da Bacia de Santos do Aptiano ao Cretaceo superior. Dissertação de Mestrado, Instituto de Geociências, Universidade Federal do Rio Grande do Sul, 201p.

Ge H., Jackson M.P.A., Vendeville B.C. 1997. Kinematics and Dynamics of Salt Tectonics Driven by Progradation. AAPG Bulletin, 81:398-423.

Gonçalves A., Oliveira M.A.M.D., Motta S.D.O. 1979. Geologia da Bacia de Pelotas e da Plataforma de Florianópolis. Boletim de Geociências da Petrobrás, 22:157-174.

Karner G.D. \& Driscoll N.W. 1999. Tectonic and stratigraphic development of the West African and eatern Brasilian margins, insights from quantatividade basin modelling. Geological Society Special Publication, 153:11-40.

Macedo J.M. 1987. Evolução estrutural da Bacia de Santos e áreas continentais adjacentes. Dissertação de Mestrado, Departamento de Geologia, Universidade Federal de Ouro Preto, $173 \mathrm{p}$.

Macedo J.M. 1989. Evolução tectônica da Bacia de Santos e áreas continentais adjacentes. Bol. de Geociências da Petrobrás, 3:159-173. 
Macedo J.M. 1990. Evolução tectônica da Bacia de Santos e áreas continentais adjacentes. In: Raja Gabaglia G.P. \& Milani E.J. (ed.) Origem e evolução de bacias sedimentares. Rio de Janeiro, PETROBRAS, p.361-376.

Macedo J.M., Gamboa L.A.P., Ricci J.A., Caddah L.F.G., Witer W. 1998. Stratigraphic comparisons between the post-rift section of the Campos and Santos Basins, Southeastern Brazilian margin. AAPG Bulletin, 82:1936.

Magoon L.B. \& Beaumont E.A. 1999. Petroleum Systems. In: Beaumont E.A. \& Foster N.H. (ed.) Exploring for oil and gas traps. AAPG, (Treatise of Petroleum Geology), 3.1-3.34.

Magoon L.B. \& Dow W.G. 2000. Mapping the petroleum system. In: Mello M.R. \& Katz B.J. (ed.) Petroleum systems of South Atlantic margins. AAPG Memoir 73:5368.

Meisling K.M., Cobbold P.R., Mount V.S. 2001. Segmentation of an obliquely rifted margin, Campos and Santos basins southeastern Brazil. AAPG Bulletin, 85:19031924.

Mello M.R., Telnaes N., Gaglianone P.C., Chicarelli M., Brasseil S.C.R., Maxwell J.R. 1988. Organic geochemical characterisation of depositional palaeoenvironments of source rocks and oils in Brazilian marginal basins. Organic Geochemistry, 13:31-45.

Mello M.R., Kotsoukos E.A.M., Mohriak W.U., Bacoccoli G. 1994. Selected petroleum systems in Brazil. In: Magoon L.B. \& Dow W.G. (eds.) The petroleum systemfrom source to trap. AAPG Memoir, 60:499-512.

Modica C.J. \& Brush E.R. 2004. Postrift sequence stratigraphy, paleogeography, and fill history of the deepwater Santos Basin, offshore southeast Brazil. $A A P G$ Bulletin, 88:923-945.

Mohriak W.U., Macedo J.M., Castellani R.T., Rangel H.D., Barros A.Z.N., Latgé M.A.L., Ricci J.A., Mizusaki A.M.P., Szatmari P., Demercian L.S., Rizzo J.G., Aires J.R. 1995. Salt tectonics and structural styles in the deepwater province of the Cabo Frio region, Rio de Janeiro, Brazil. AAPG Memoir, 65:273-304.

Pereira M.J., Barbosa C.M., Agra J., Gomes J.B., Aranha L.G.F., Saito M., Ramos M.A., Carvalho M.D., Stamato M., Bagni O. 1986. Estratigrafia da Bacia de Santos. Análise das seqüências, sistemas deposicionais e revisão litoestratigráfica. In: SBG, Congresso Brasileiro de Geo- logia, 34, Goiânia, anais, v.1, p.65-79.

Pereira M.J., Barbosa C.M., Agra J., Gomes J.B., Aranha L.G.F., Saito M., Ramos M.A., Carvalho M.D., Stamato M., Bagni O. 1986. Estratigrafia da Bacia de Santos. Análise das seqüências, sistemas deposicionais e revisão litoestratigráfica. In: SBG, Congresso Brasileiro de Geologia, 34, Goiânia, anais, v.1, p.65-79.

Pereira M.J. \& Macedo J.M. 1990. A Bacia de Santos: perspectivas de uma nova província petrolífera na plataforma continental sudeste brasileira. Boletim Geociências da Petrobrás, 4:3-11.

Pereira M.J. 1990. Análise estratigráfica e depositional das formações Itajaí superior e Juréia inferior (Mesoturoniano/Eo-Santoniano), Bacia de Santos, Brasil. Dissertação de Mestrado, Instituto de Geociências, Universidade Federal do Rio de Janeiro, 165p.

Pereira M.J. \& Feijó F.J. 1994. Bacia de Santos. Estratigrafia das Bacias Sedimentares do Brasil. Boletim de Geociências da Petrobrás, 8:219-234.

Pereira M.J. 1994. Seqüências deposicionais de $2^{a} / 3^{a}$ ordens (50 a 2,0 Ma) e tectono-estratigrafia no Cretáceo de cinco bacias marginais do Brasil. Comparações com outras áreas do globo e implicações geodinâmicas. Tese de Doutoramento, Instituto de Geociências, Universidade Federal do Rio Grande do Sul, Porto Alegre, 271p.

Sombra C.L., Arienti L.M., Pereira M.J., Macedo J.M. 1990. Parâmetros controladores da porosidade e permeabilidade nos reservatórios clásticos profundos do Campo de Merluza, Bacia de Santos, Brasil. Bol. Geoc. Petrobrás, 4:451-466.

Szatmari P., Guerra M.C.M., Pequeno M.A. 1994. Physical modelling of a giant antithetic fault formed by salt flow in the Santos Basin (Offshore SE Brasil). In: Internacional Sedimentalogical Cogress, Netherlands, v.14, p.F24F25.

Viviers M.C. \& Azevedo R.L.M. 1988. The southeastern area of the Brazilian continental margin: its evolution during the Middle and Late Cretaceous, as indicated by paleoecological data. Revista Bras. de Geociências, 18:291298.

Manuscrito BR 18

Submetido em 21 de dezembro de 2007 Aceito em 29 de abril de 2008 